\title{
Çoklu Zamanlı Sentinel-2 Görüntülerinden Tarımsal Ürün Tespiti: Mardin - Kızıltepe Örneği
}

\author{
Müslüm ALTUN ${ }^{1 *}$, Mustafa TÜRKER ${ }^{2}$ \\ 1,2 Hacettepe Üniversitesi, Mühendislik Fakültesi, Geomatik Mühendisliği Bölümü, Ankara. \\ *Sorumlu yazar e-posta: altunmuslum06@gmail.com ORCID ID: http://orcid.org/0000-0002-5603-6331 \\ mturker@hacettepe.edu.tr ORCIDID: http://orcid.org/0000-0001-5604-0472 \\ Geliş Tarihi: 03.03.2021 Kabul Tarihi: 14.08.2021
}

\section{Anahtar kelimeler Sentinel 2; Makine Öğrenme Algoritması; Rastgele Orman (RO) Sınıflandırma Tekniği; Çiftçi Kayıt Sistemi} (ÇKS)

\section{Öz}

Bu çalışmada, Mardin İli, Artuklu, Kızıltepe ve Derik illçelerinde tarımsal arazilerden oluşan bir bölgede, 2018 yılına ait çoklu tarihli Sentinel-2 uydu görüntülerinden sınıflandırma yöntemi ile ürün tespiti yapılmıştır. Sınıflandırmada, Rastgele Orman (RO) algoritması parsel-tabanlı yaklaşımla kullanılmıştır. Tespit edilen ürünler mısır, buğday, pamuk, nohut, mercimek ve diğerleridir. Görüntü olarak altı farklı tarihte (8 Nisan, 23 Mayıs, 12 Temmuz, 11 Ağustos, 5 Eylül ve 5 Ekim) çekilmiş görüntüler seçilmiştir. Sınıflandırmada 10m konumsal çözünürlüklü Mavi (M), Yeşil (Y), Kırmızı (K) ve Yakın Kızı Ötesi (YKÖ) bantlar kullanılmıştır. Ayrıca, her bir görüntü tarihi için Normalize Edilmiş Fark Bitki Örtüsü İndeksi (NFBi) bandı hesaplanmış ve sınıflandırmada ek bant olarak kullanılmıştır. RO algoritması ile sınıflandırma işlemi, her bir görüntü tarihine ait beş bant ( $M, Y, K, Y K O ̈$ ve NFBi) olmak üzere, toplam 30 bantlı görüntü yığınının tek seferde sınıflandırmaya dâhil edilmesi şeklinde gerçekleştirilmiştir. Eğitim alanı örnekleri ve sonuçların doğruluk analizleri için, mevcut Çiftçi Kayıt Sistemi (ÇKS) verilerinden yararlanılmıştır. Sınıflandırma neticesinde \% 96.35 genel doğruluk ve \% 93.13 kappa katsayısı değerlerine ulaşılmıştır.

\section{Agricultural Crop Detection from Multi-Temporal Sentinel 2 Images: A Case Study of Mardin - KızItepe}

Keywords

Sentinel 2; Machine Learning Algorithm; Random Forest (RF)

Classification Technique; Farm Registration System (FRS)

\begin{abstract}
In this study, crop detection was carried out in an agricultural region in the Artuklu, Kızıltepe and Derik districts of the city of Mardin through classification of multi-temporal Sentinel-2 images from 2018. In the classification, the Random Forest (RF) algorithm was used through a parcel-based approach. The detected crops are corn, wheat, cotton, chickpeas, lentils and the others. The images acquired on six different dates (April 8, May 23, July 12, August 11, September 5 and October 5 ) were selected as the images. In the classification, the $10 \mathrm{~m}$ spatial resolution bands Blue (B), Green (G), Red (R) and Near Infrared (NIR) were used. Furthermore, for each image date a Normalized Difference Vegetation Index (NDVI) band was computed and used as additional band in classification. The classification process through the RF algorithm was carried out using the stack of 30 bands that includes five bands $(B, G, R$, NIR, NDVI) for each image. For training samples and the accuracy assessment of the results, the existing Farmers' Registry System (FRS) was utilised. As a result of the classification process, the overall accuracy of $96.35 \%$ and the Kappa value of $93.13 \%$ were achieved.
\end{abstract}

(c) Afyon Kocatepe Üniversitesi

\section{Giriş}

Uzaktan algılama, karasal dinamiklerin farklı mekânsal ve zamansal çözünürlüklerle uygun şekilde gözlemlenmesini, tanımlanmasını, haritalanmasını, değerlendirilmesini ve izlenmesini sağlayan bilim dalıdır. Uzaktan algılamanın avantajlarının en iyi şekilde kullanılabildiği alanlardan biri, dinamik arazi örtüsüne sahip olan tarım alanlarıdır (Rodriguez-Galiano et al. 2012). Uzaktan algılama teknolojisi günümüzde tarımsal ürün tespitinde çok yaygın olarak kullanılmaktadır. Tarım arazilerinin uydu görüntüleri ile haritalanması 
konusunda çeşitli ölçeklerde farklı çalışmalar vardır (Thenkabail et al. 2010, Gumma et al. 2011, Thenkabail et al. 2011). Uzaktan algılama çalışmalarında kullanılacak veri temini zaman ve maliyet analizi açısından oldukça pahalıdır. Sentinel2 uydu görüntülerinin ücretsiz olarak temin edilebilmesi bu güçlüğün ortadan kaldırılmasında oldukça önemlidir. Ayrıca, Sentinel-2 uydusu zengin bant sayısı, kullanıcılara farklı konumsal çözünürlükte görüntü sunması ve düşük zamansal çözünürlük özelliği ile çoklu tarihli görüntüleri kısa sürede kullanıma kazandırması açısından birçok farklı alanda yaygın kullanımı ile ön plana çıkmaktadır. Bu özellikleri ile Sentinel-2 uydusunun yaygın kullanım alanlarından birisi de tarımsal alanlardır.

Uydu görüntülerinin tarımsal alanlarda en yaygın kullanımlarından birisi ürün tespitidir. Otomatik görüntü sınıflandırma ile ürün tespitinde oldukça başarılı sonuçlar elde edilebilmektedir (Thenkabail and Wu 2012, Dheeravath et al. 2010, Brisco and Brown 1995, Ban 2003, Inglada et al. 2016). Otomatik görüntü sınıflandırma ile tarımsal ürün tespiti, verim ve rekolte tahmini gibi tarımsal ekosistem değişkenlerinin modellenmesini de sağlar (Wesseling and Fedes 2006). Tarımsal ürün deseni tespitinde çok zamanlı uydu görüntüleri ile yapılan çalışmaların tek zamanlı uydu görüntüleri ile yapılan çalışmalara göre çok daha yüksek doğruluk verdiği bilinmektedir (Gömez et al. 2016, Long et al. 2013). Vuolo et al. (2018) tarafından Avusturya'nın Marchfeld bölgesindeki tarımsal alanlarında 2016 ve 2017 yılları Mart ve Nisan aylarında çekilen Sentinel2 uydu görüntüleri kullanılarak havuç, mısır, soğan, patates, kabak, soya fasulyesi, şeker pancarı ve ayçiçeği sınıfları olmak üzere toplam 8 adet yaz ürünü ve 1 adet kış ürünü (kış tahılı) olmak üzere toplam 9 sınıf tanımlanarak sınıflandırma yapılmıştır. Kırmızı-K, Yeşil-Y, Mavi-M ve Yakın Kızıl Ötesi-YKÖ olmak üzere 4 bantla yapılan sınıflandırmada, 2016 yılı görüntülerinde 5219 adet parsel üzerinde \% 95,80 genel sınıflandırma doğruluğu, 2017 yılı görüntülerinde 5085 adet parsel üzerinde \% 94,60 genel doğruluk elde edilmiştir. Turker ve Arikan (2005) tarafından 2005 yılında Bursa ili Karacabey ilçesinde Mayıs, Temmuz ve Ağustos aylarına ait Landsat-7 ETM+ görüntüleri ile parsel tabanlı tarımsal ürün tespiti çalışmasında \% 81,30 genel sınıflandırma doğruluğu elde edilmiştir. Sonobe et al. (2017) tarafından Japonyanın Hokkaido bölgesinde çoklu zamanlı Sentinel-1 ve Sentinel-2 görüntüleri kullanılarak 6 farklı tarımsal ürün sınıflandırılmıştır. 2016 yılının 5 farklı tarihine ait görüntüler ile Kernel Temelli Aşırı Öğrenme Makinesi (KELM), Çok Katmanlı Ileri Beslemeli Sinir Ağları, Rastgele Orman (RO) ve Destek Vektör Makineleri (DVM) olmak üzere 4 farklı yaklaşım denenmiştir. KELM yaklaşımı \% 96,80 ile en yüksek sınıflandırma performansını vermiştir. Simonneaux et al. (2008) tarafından Marrakech Central Morocco'da yapılan çalışmada çıplak toprak, yıllık bitkiler, çıplak toprak üstündeki ağaçlar ve alt bitki örtüsü üstündeki ağaçlar olmak üzere 4 ana sınıf tanımlanarak 8 zaman serili Landsat TM görüntüleri ile ürün tespiti yapılmıştır. Karar ağacı algoritması ile yapılan sınıflandırmada \% 83,70 genel doğruluk ve 0,78 kappa katsayısı değerleri hesaplanmıştır. Sakamoto et al. (2005) tarafından Japonya'da $250 \mathrm{~m}$ konumsal ve 16 gün zamansal çözünürlüklü 2002 yılına ait çoklu zamanlı MODIS Geliştirilmiş Bitki İndeksi (Enhanced Vegetation Index- EVI) ile pirinç ürünü sınıflandırılması işlemi başarılı bir şekilde gerçekleştirilmiştir. Arvor et al. (2011) tarafından yapılan çalışmada MODIS-Terra Geliştirilmiş Bitki İndeksi (Enhanced Vegetation Index-EVI) zaman serileri ile Brezilyanın Mato Grosso eyaletinde soya fasulyesi, misır, pamuk ve ticari olmayan ürünler olmak üzere 4 sınıf tanımlanarak sınıflandırma işlemi yapılmıştır. En yüksek olasılık (Maximum Likelihood) sınıflandırma algoritması kullanılarak genel sınıflandırma ve kappa katsayısı doğrulukları sırasıyla \% 85,50 ve 0,8067 olarak hesaplanmıştır. Peña-Barragán et al. (2011) tarafından yapılan çalışmada farklı tarihlerde alımı yapılan 3 adet ASTER (Advance Spaceborne Thermal Emission and Reflection Radiometer - Gelişmiş Uzay Termal Emisyon ve Yansıma Radyometresi) uydu görüntüsü kullanılarak ABD'nin Kalifornia eyaletinde tarımsal ürün tespiti yapılmıştır. 13 tarımsal ürünün tanımlandığı karar ağacı modeli algoritması ile gerçekleştirilen sınıflandırma çalışmasında genel doğruluk oranı \%79 olarak hesaplanmıştır.

Immitzer et al. (2016) tarafından Avustralya'nın Marchfeld bölgesinde yapılan bir çalışmada 
Sentinel-2 uydusunun $20 \mathrm{~m}$ çözünürlüklü bantları 10 m'ye yeniden örneklenmiş ve $10 \mathrm{~m}$ konumsal çözünürlüklü bantları ile birleştirilmiştir. Yaklaşık 10 km x 10 km'lik çalışma alanında RO algoritması kullanılarak havuç, mısır, soğan, soya, şeker pancarı, ayçiçeği ve kış ürünleri olmak üzere toplam 7 adet tarımsal ürün sınıfı tanımlanmış olup, \%90 oranında genel doğruluk elde edilmiştir. Topaloğlu vd. (2016) tarafından yapılan bir çalışmada Sentinel-2 ve Landsat-8 uydusu görüntüleri ile yapılan sınıflandırma işleminin doğruluklarını karşılaştırma amaçı ı̇stanbul ilinde $309,02 \mathrm{~km}^{2}$ 'lik alanda sınıflandırma yapılmıştır. Landsat-8 uydusunun $30 \mathrm{~m}$ çözünürlüklü 6 bandı ve Sentinel-2 uydusunun $10 \mathrm{~m}$ ve $20 \mathrm{~m}$ çözünürlüklü 6 bandı $30 \mathrm{~m}$ çözünürlüğe yeniden örneklenerek farklı uyduların aynı konumsal çözünürlüklü görüntüleri kullanılarak işlem gerçekleştirilmiştir. Su, orman, çimen alanı, yeşil alan, yol, kırsal alan, havaalanı/sanayi alanı, maden/kıraç alanı olmak üzere 8 adet sınıf tanımlanmıştır. En Yüksek Olasılık algoritması ve destek vektör makineleri (DVM) algoritması kullanılarak Sentinel-2 ve Landsat-8 görüntüleri kullanılarak ENVI yazııımında sınıflandırma işlemi yapılmış olup, farklı kombinasyonlarda genel doğruluk değerleri hesaplanmıştır. En yüksek olasılık algoritması ile; Landsat-8 uydu görüntüleri kullanılarak \%70,60 genel doğruluk, Sentinel-2 uydu görüntüleri kullanılarak \%76,40 genel doğruluk değerleri hesaplanmıştır. DVM algoritması ile; Landsat-8 uydu görüntüleri kullanılarak \%81,67 genel doğruluk, Sentinel-2 uydu görüntüleri kullanılarak \% 84,17 genel doğruluk değerleri hesaplanmıştır. İrfanoğlu ve Balçık (2018) tarafından 2018 yılında İstanbul ili, Çatalca ilçesinde, Sentinel-2 uydusunun $10 \mathrm{~m}$ çözünürlüklü $\mathrm{K}, \mathrm{Y}, \mathrm{M}$ ve YKÖ bantları kullanılarak çoklu çözünürlük segmentasyon ve ardından nesne-tabanlı sınıflandırma işlemi yapılmıştır. Sınıflandırma doğruluğunu artırmak için $K, Y, M$ ve YKÖ bantlarından Normalize Edilmiş Fark Bitki İndeksiNFBi (Normalized Difference Vegetation IndexNDVI), Homojenlik (Gray Level Co-occurance MatrixGLCM), Toprak Dengelemeli Bitki İndeksi (Soil Adjusted Vegetation Index-SAVI) ve Normalize Edilmiş Fark Su Indeksi (Normalized Difference Water Index-NDWI) bantları hesaplanarak sınıflandırma işlemine dâhil edilmiş ve \% 91,30 genel doğruluk ve 0,89 kappa katsayısı değerleri hesaplanmıştır. Ek bantlar ile sınıflandırma doğruluğunun arttığı gözlemlenmiştir. Belgiu and Csillik (2018) tarafından Romanya (1. bölge), ìtalya (2. bölge) ve Amerika Birleşik Devletleri'nde (3. bölge) Sentinel-2 uydu görüntülerinden 1. bölge için 5 sınıf, 2. bölge için 6 sınıf ve 3 . Bölge için 7 sınıf tanımlanarak segmentasyon ve sınıflandırma yapılmıştır. Çalışmada NFBi ek bandı hesaplanarak RO tekniği ile yapılan sınıflandırmada 1. bölge için \% 92,62 , 2. bölge için $\% 87,11$ ve 3 . bölge için $\% 66,56$ genel doğruluk oranları elde edilmiştir.

MODIS, ASTER, Landsat-7 ETM+ ve Landsat-8 TM uydu görüntüleri bazı çalışmalarda halen kullanılmasına rağmen, günümüz teknolojisi ile kıyaslandığında konumsal çözünürlükleri düşüktür. Diğer yandan orta, yüksek ve çok yüksek konumsal çözünürlüklü uydu görüntülerinin temini yapılan çalışmalardan beklenen sonuçlara pozitif yönde katkıda bulunmuştur (Powell et al. 2007). Pirotti et al. (2016) tarafından İtalya'nın Padova şehrinde yapılan çalışmada Sentinel-2 uydu görüntüleri kullanılarak yaklaşık 60 km2 'lik bir alanda yapay sinir ağları tekniği kullanılarak sınıflandırma işlemi yapılmıştır. Çalışma alanı içerisine rastgele atılan noktalar ile doğruluk değerlendirmesi yapılmış ve yaklaşık \%90 genel doğruluk elde edilmiştir. Noi and Kappas (2018) tarafından yapılan Vietnam'ın Kızıl Nehir bölgesinde bir tarımsal alanda sınıflandırma işlemi yapılmıştır. SNAP yazılımının kullanıldığı bu çalışmada, Sentinel-2 uydusunun $10 \mathrm{~m}$ ve $20 \mathrm{~m}$ çözünürlüklü bantları birleştirilerek RO, En Yakın Komşuluk ve DVM sınıflandırma algoritmaları kıyaslanmıştır. Yerleşim alanı, geçirimsiz yüzey, tarım alanı, çıplak alan, orman ve su olmak üzere 6 adet sınıf tanımlanarak sınıflandırma işlemi gerçekleştirilmiştir. En Yakın Komşuluk algoritması ile \%94,59 genel doğruluk, RO algoritması ile $\% 94,70$ genel doğruluk ve DVM algoritması ile \%95,32 genel doğruluk değeri elde edilmiştir.

Gasparovic and Jogun (2017) tarafından Batı Hırvatistan'ın Rijeka şehrinde 60 km x 60 km'lik bir alan içinden seçilen $1,5 \mathrm{~km} \times 1,5 \mathrm{~km}$ 'lik test alanında arazi örtüsü tespiti amaçlı sınıflandırma yapılmıştır. Çalışmada Sentinel-2 uydusunun farklı bantlarının 
kaynaştırılarak işleme dâhil edilmesi ve bunun sınıflandırmaya etkisi araştırılmıştır. Farklı görüntü kaynaştırma teknikleri kullanılarak SNAP yazııımında su, yerleşim alanı, çıplak alan, yeşil alan ve orman olmak üzere 5 farklı sınıf tanımlanmıştır. Yapay Sinir Ağları tekniği ile yapılan sınıflandırma sonucunda en yüksek genel doğruluk oranı \% 74,90 olarak hesaplanmıştır.

Bu çalışmada çoklu tarihli Sentinel-2 uydu görüntülerinden Mardin ili, Artuklu, Kızıltepe ve Derik ilçeleri sınırları içinde kalan tarım alanlarının bir kısmında RO sınıflandırma algoritması kullanılarak parsel-tabanlı yaklaşımla yaz aylarında yetiştirilen tarım ürünlerinin tespiti yapılmıştır. Sınıflandırmada $10 \mathrm{~m}$ çözünürlüklü $K, Y, M$ ve YKÖ bantlar kullanılmıştır. Seçilen her bir görüntü tarihi için K ve YKÖ bantlardan NFBi bantları hesaplanmış ve sınıflandırmada ek bantlar olarak kullanılmıştır. RO sınıflandırma algoritmasının iki önemli parametresi olan ntree ve mtry değerleri, Breiman (2018), Breiman (2001), Pal (2005) ve Archer and Kimes (2008) tarafından yapılan çalışmalarda önerildiği şekilde belirlenmiştir.

\section{2. Çalışma Alanı, Uydu Görüntüleri ve Arazi Verileri}

\section{1 Çalışma alanı}

Çalışma alanı (Şekil 1) Mardin Ili, Artuklu, Kızıltepe ve Derik ilçeleri sınırları içinde yer alan bir tarımsal alandan oluşmaktadır. Yaklaşık koordinatları 600000.00 m, 4138360.00 m (Kuzey Batı); $600000.00 \mathrm{~m}, 4090200.00 \mathrm{~m}$ (Güney Batı); 668980.00 m, 4138360.00 m (Kuzey Doğu); 668980.00 m, 4090200.00 m (Güney Doğu) olan çalışma alanının projeksiyon bilgileri şu şekildedir: WGS 84, UTM-Zone 37 N, DOM 39. Çalışma alanında farklı özelliklere (örn., ekim zamanı, yaprak türü ve yaprak dökme zamanı, hasat zamanı, yıl içinde hasat edilme sıklığı v.b.) ve farklı büyüklükte parsellere sahip tarımsal yaz ürünleri bulunmaktadır. Bölgede temel olarak mısır, buğday, pamuk, nohut ve mercimek yaz ürünleri bulunmakla birlikte yaygın olarak üretimi yapılan ürünlere göre nispeten daha küçük parseller içerisinde ekili farklı ürünler de mevcuttur. Çalışma alanının büyük bir bölümü ekili tarımsal alanlardan oluşmasına rağmen, alımı yapılan görüntü tarihi itibariyle ekili olmayan nadas alanları da bulunmaktadır.

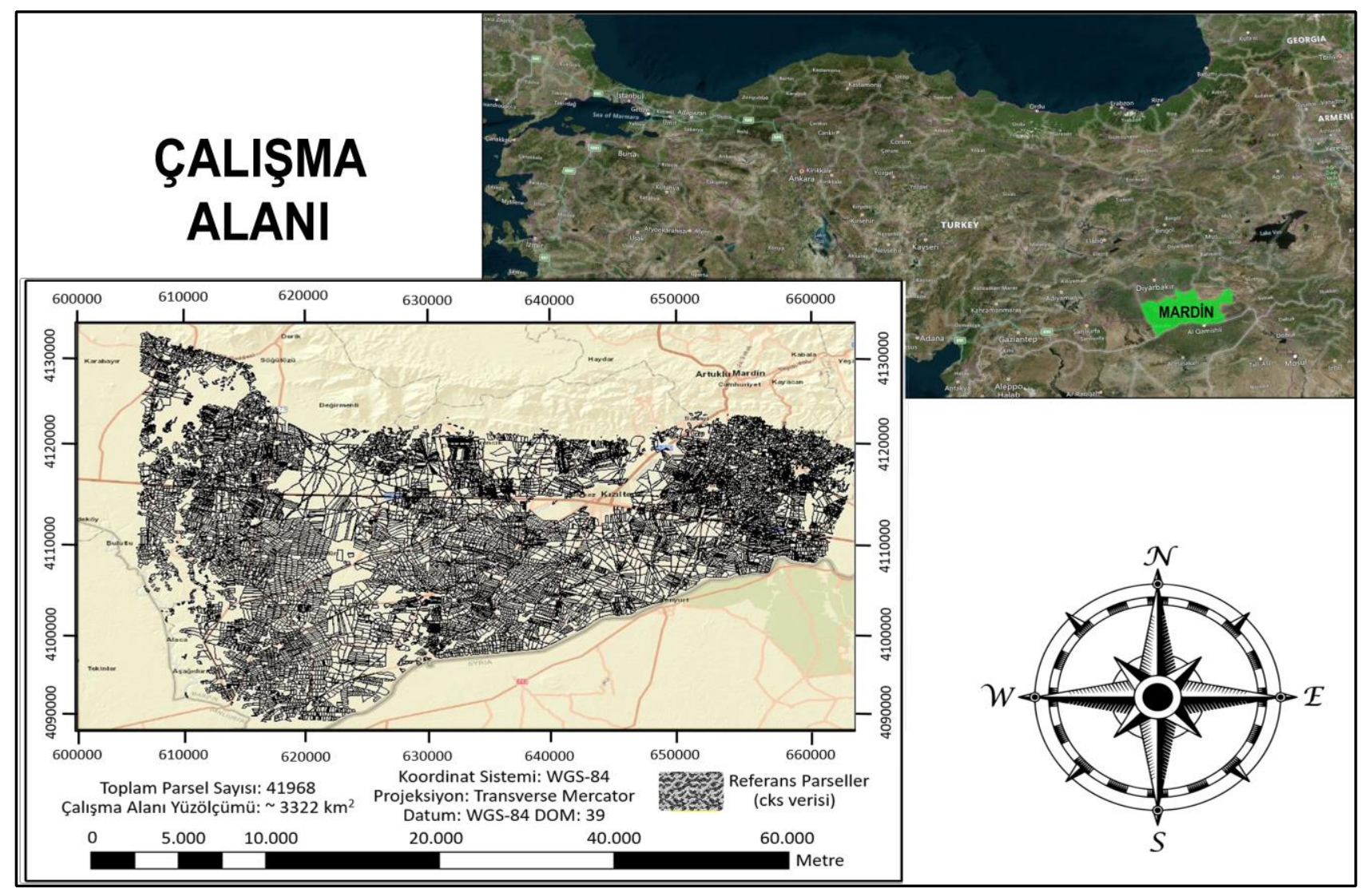

Şekil 1. Çalışma alanının görünümü. 


\subsection{Sentinel- 2 uydu görüntüleri}

Çalışmada 6 farklı tarihe ait Sentinel-2 uydu görüntüleri kullanılmıştır (Çizelge 1). Görüntüler Earthexplorer (Int Kyn. 1) web sitesinden ücretsiz olarak temin edilmiştir. Görüntü tarihlerinin seçimi, her aya ait tüm görüntülerin görsel incelenmesine göre yapılmıştır. Her bir görüntü için indirilen dosyada, görüntülerin 13 bandının (Bant 1-Kıyı Aerosol, Bant 2-Mavi, Bant 3-Yeşil, Bant 4-Kırmızı, Bant 5-Bitki Sıcak Kenar, Bant 6-Bitki Sıcak Kenar, Bant 7-Bitki Sıcak Kenar, Bant 8-Yakın Kızıl Ötesi, Bant 8A- Bitki Sıcak Kenar, Bant 9-Su Buharı, Bant 10-Kısa Dalga Kızıl Ötesi, Bant 11- Kısa Dalga Kızıl Ötesi, Bant 12- Kısa Dalga Kızıl Ötesi) her birine ait görüntü dosyası, meta veri, geometrik ve radyometrik düzeltme bilgileri vb. yer almaktadır.

Sentinel-2 uydusu, 5 günlük zamansal çözünürlüğe, geniş şerit genişliğine, farklı konumsal çözünürlüklerde $(10 \mathrm{~m}, 20 \mathrm{~m}, 60 \mathrm{~m}) 13$ spektral banda sahiptir. Bu özellikleri ile Sentinel-2 uydusu görüntüleri diğer çok bantlı uydu görüntüleri arasında öne çıkmaktadır ve tarımsal alanların gözlemlenmesi, tarımsal ürün türlerinin tespit edilmesi, bitki örtüsü ve yeryüzünün izlenmesi için detaylı bir bakış açısı sunmaktadır.

Çizelge 1. Çalışmada kullanılan uydu görüntüleri.

\begin{tabular}{lc}
\hline Uydu & Görüntü Tarihi \\
\hline Sentinel 2 & 08.04 .2018 \\
\hline Sentinel 2 & 23.05 .2018 \\
\hline Sentinel 2 & 12.07 .2018 \\
\hline Sentinel 2 & 11.08 .2018 \\
\hline Sentinel 2 & 05.09 .2018 \\
\hline Sentinel 2 & 05.10 .2018 \\
\hline
\end{tabular}

\subsection{Yersel referans veriler}

T.C. Tarım ve Orman Bakanlığı'nca oluşturulan Çiftçi Kayıt Sistemi (ÇKS), çiftçilere ait tarımsal faaliyetlerin kayıt altına alındığı bir veri tabanıdır. Bu çalışmada alana ait ÇKS verisi (Şekil 2), yersel referans veri olarak kullanılmıştır. ÇKS verisi parsel sınırları ile parsellere ait öznitelik verileri içerir. Öznitelik veriler arasında veri tipi, tapu kaydı bilgileri (il, ilçe, mahalle, ada ve parsel numarası), zemin referans numarası, toplam parsel yüzölçümü, ekili alan yüzölçümü, ekili ürün adı ve toplam parsel yüzölçümü ile ekili alan yüzölçümü arasındaki fark bilgileri yer almaktadır.

Çalışma alanında toplam 41968 adet parsel bulunmaktadır. Yapılan incelemelerde bazı parsellerde ÇKS öznitelik verileri ile ÇKS verisinin arazide temsil ettiği parseller (fiziksel yeryüzü) arasında farklılık olduğu görülmüştür. Örneğin, bazı parsellerde ÇKS verisi ile parsel ekili alan yüzölçümü aynı değildir. Bazı parsellerde ise ekili olduğu belirtilen alanın ekilmediği görülmüştür. Bu durum ÇKS verisinin öznitelik bilgisi ile parsel malik bilgisini ilişkilendirmede karışıklığa neden olmuştur. Birden fazla maliki olan parsellerin bulunması durumu da (hisseli mülkiyet) parsellerin fiziksel temsili ile ÇKS öznitelik verisi arasında uyuşumsuzluğa sebep olan bir diğer neden olarak gözlemlenmiştir. Bu olası uyuşumsuzluk ve karışıklığı gidermek amacıyla, ÇKS verisi üzerinde otomatik ve manuel yöntemlerle gerekli düzenleme ve silme işlemleri gerçekleştirilmiş olup, kalan 5803 parsel çalışmada referans veri olarak kullanılmıştır. 


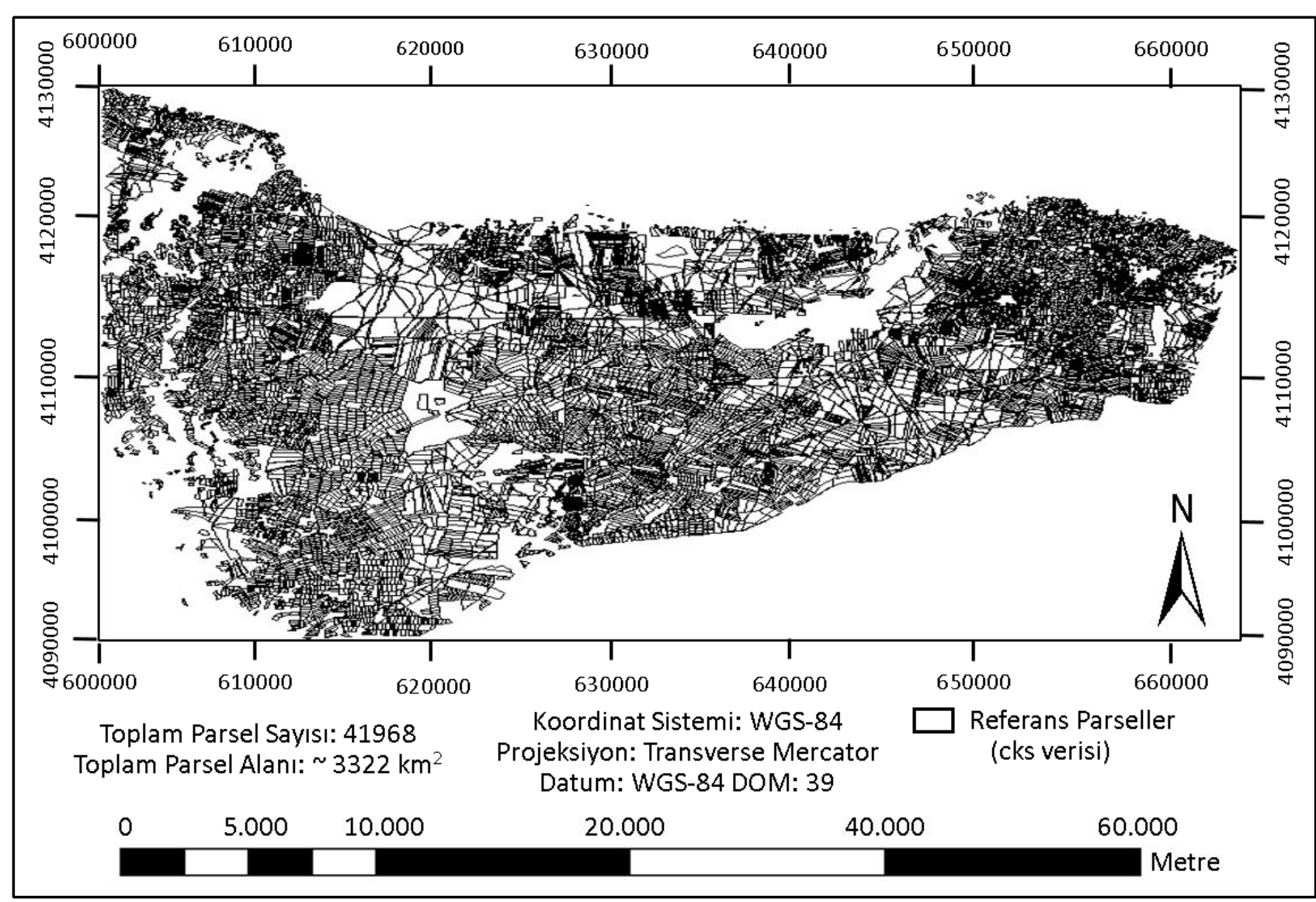

Şekil 2. 2018 yılı ÇKS verisi parsel sınırlar.

\section{Yöntemler}

Yöntemin adımlarını özetleyen akış diyagramı Şekil 3'de gösterilmiştir. Yöntem, veri ön işlemeleri, sınıflandırma ve doğruluk analizleri olmak üzere üç temel adımdan oluşmaktadır. illk olarak, görüntülerde sınır piksellerinin işlem dışı bırakılması ve çoklu görüntü bantları yığınının oluşturulması işlemleri yapılarak veriler sınıflandırılmaya hazır hale getirilmiştir. Sonra, referans veri olarak kullanılabilmesi için, ÇKS verisi üzerinde gerekli düzenleme işlemleri gerçekleştirilmiştir. Veri ön işlemeleri temel adımı altındaki daha sonraki aşamada ise, sınıflandırma işleminde ek bant olarak kullanılmak üzere altı farklı tarihli görüntü için $\mathrm{K}$ ve YKÖ bantlardan NFBi bantları hesaplanmıştır. Yöntemin ikinci adımında, oluşturulan RO modeli algoritması kullanılarak çoklu tarihli görüntülerin parsel-tabanlı yaklaşımla sınıflandırma işlemi yapılmıştır. Son adım olarak, kullanılan algoritmanın çalışma alanı üzerindeki performansını ölçmek amacıyla doğruluk analizleri yapılmıştır. 


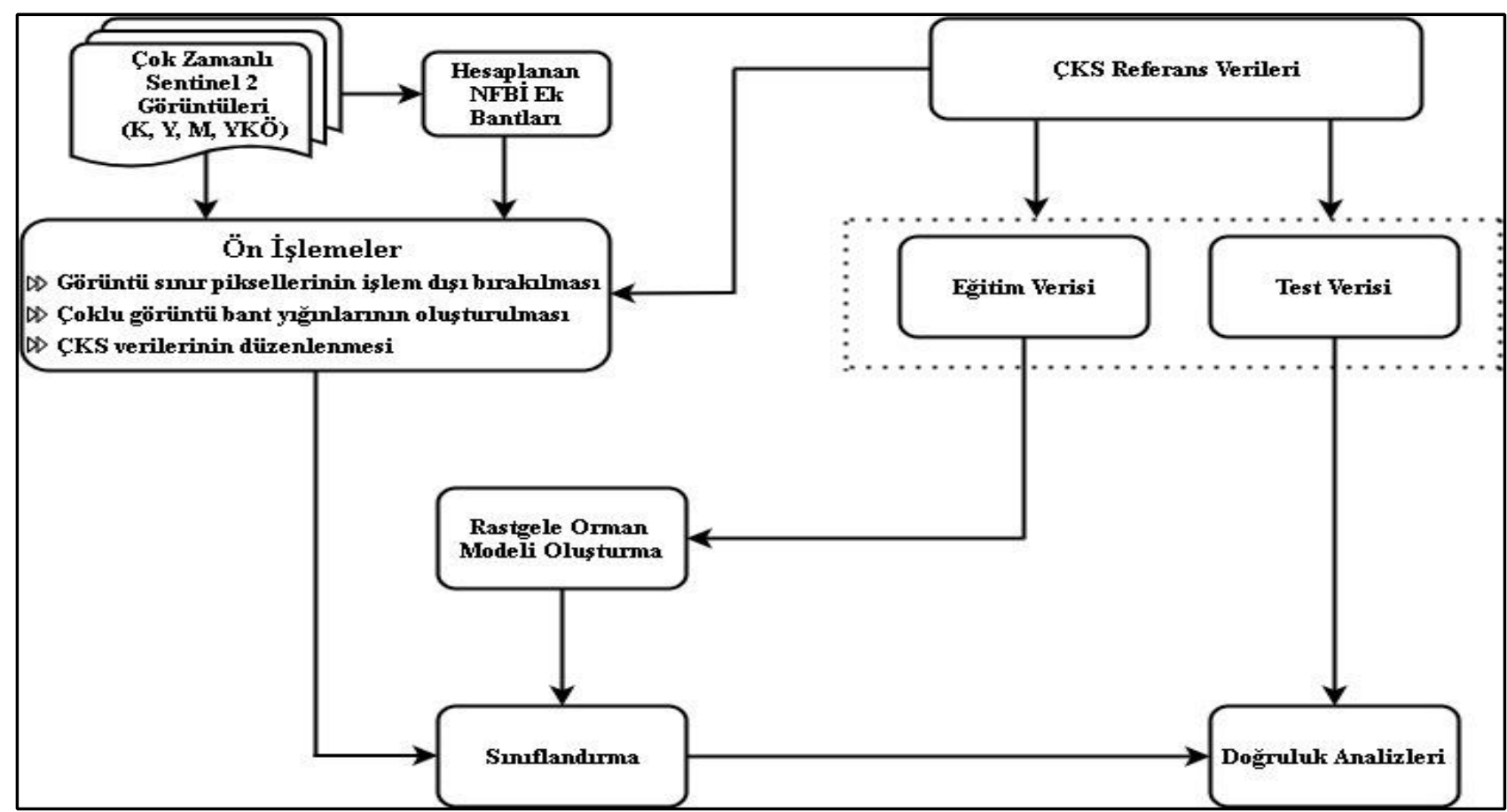

Şekil 3. Yöntemin akış diyagramı.

\section{1 Ön işlemeler}

Bu çalışmada görüntülerin $10 \mathrm{~m}$ çözünürlüklü bantları kullanılmıştır. $\mathrm{Bu}$ nedenle, ArcGıS yazılımında, her bir görüntü tarihi için, $10 \mathrm{~m}$ çözünürlüklü bantlardan (Band $2(\mathrm{~K})$, Band $3(\mathrm{Y})$, Band 4 (M) ve Band 8 (YKÖ)) çoklu görüntü bantları yığını oluşturulmuştur (Int Kyn. 2). Çalışma alanına ait 08.04.2018 tarihli Sentinel-2 görüntüsü (Gerçek Renk-K, Y, M) ve ÇKS parselleri Şekil 4'te gösterilmiştir.

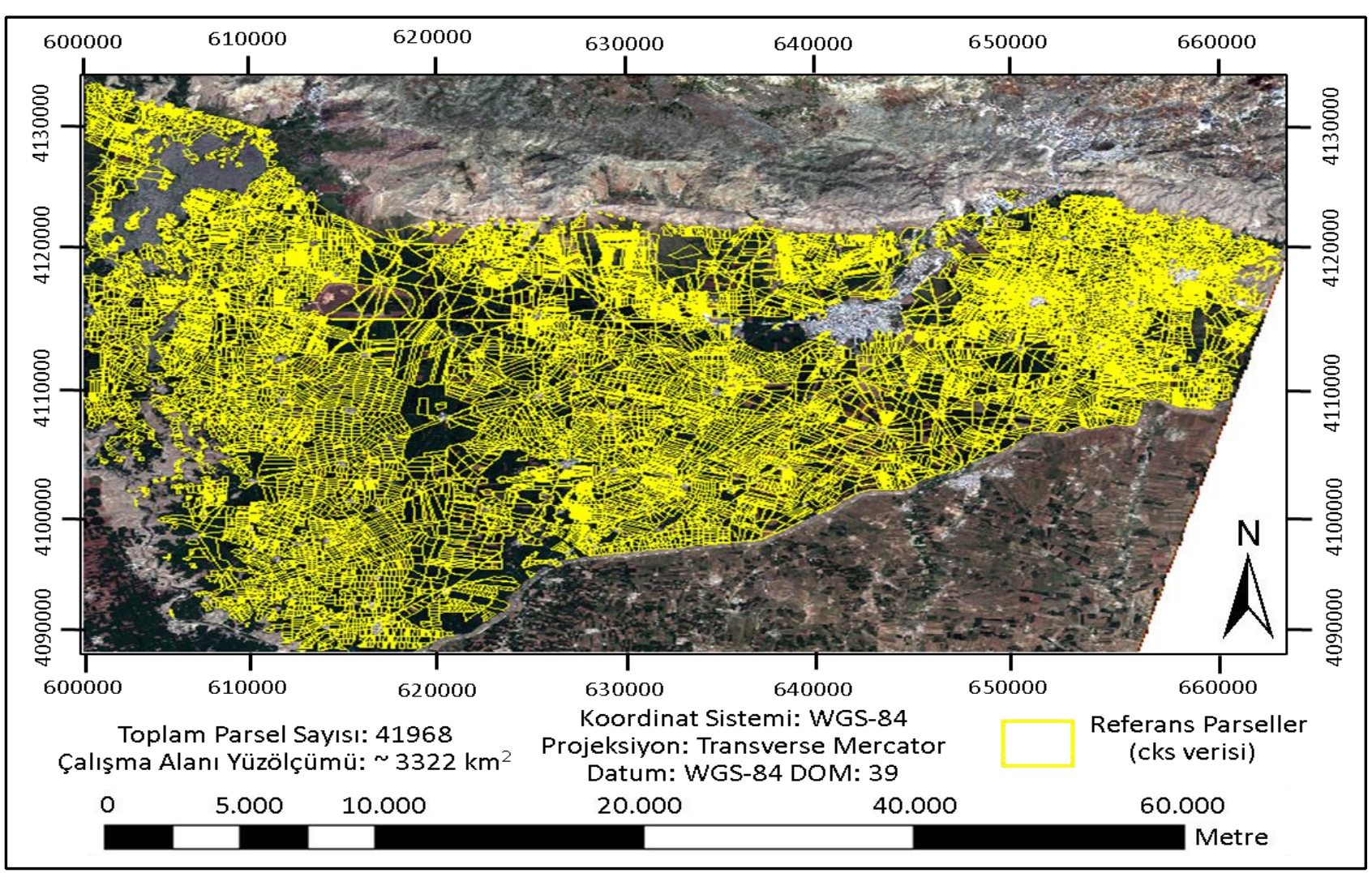

Şekil 4. Çalışma alanına ait 08.04.2018 tarihli Sentinel 2 görüntüsü (Gerçek Renk-K, Y, M) ve ÇKS parselleri. 
Çalışmada yersel referans veri olarak kullanılan ÇKS verilerine de gerekli düzenleme işlemleri yapılmıştır. Önce, ÇKS verisi öznitelik bilgileri uydu görüntülerinin metaverileri ile ilişkilendirilmiştir. Sonra, $1000 \mathrm{~m}^{2}$ nin altında içinde ekili ürün olmayan çok sayıda parsel olması nedeniyle, ÇKS verisi öznitelik tablosundaki "Ekili Alan" sütununda 1000 $\mathrm{m}^{2}$ 'nin altındaki parseller elimine edilmiştir. Tüm bu düzenleme, ayıklama ve elimine etme işlemlerinden sonra, ÇKS verisinde kalan parseller referans veri olarak kullanılmak üzere kaydedilmiştir (Şekil 5).

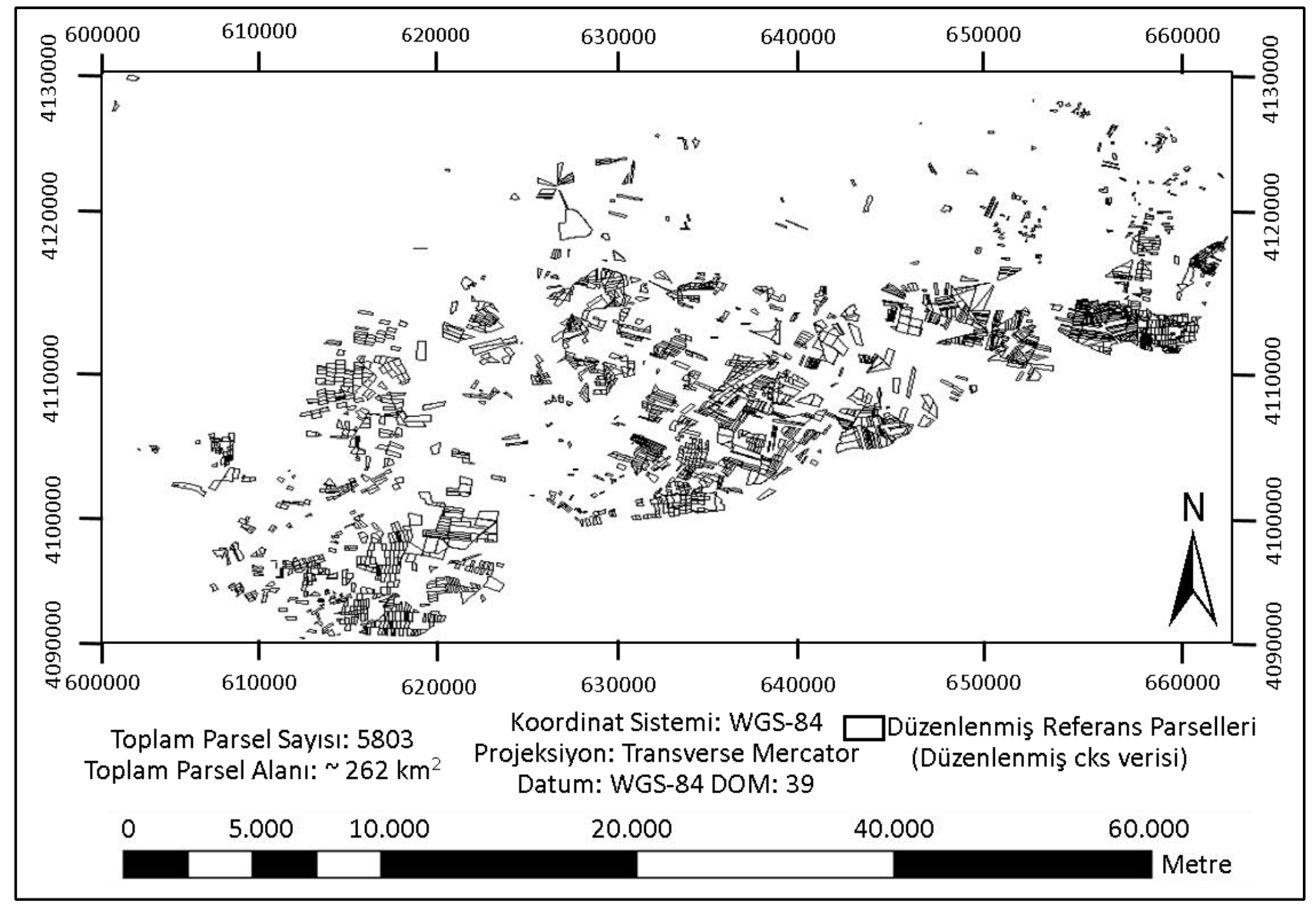

Şekil 5. Düzenleme sonrası sınıflandırmada referans veri olarak kullanılan ÇKS parselleri.

\subsection{Görüntü sınıflandırma}

Görüntü sınıflandırma işlemi MATLAB R2019b ortamında RO makine öğrenme algoritması ile gerçekleştirilmiştir (Int Kyn. 3). Sınıflandırmada, piksel grupları ile işlem yapılan parsel-tabanlı yaklaşım kullanılmıştır. Parsel-tabanlı yaklaşımda piksellerin şekil, renk, doku, büyüklük, ilişki ve desen gibi belirli özelliklerine göre piksel grupları oluşturulup, işlemler bu piksel grupları üzerinden yapılmaktadır. Bu çalışmada piksel grupları, ÇKS verisinde yer alan her bir parselin içine düşen piksel topluluklarınca oluşturmuştur ve sınıflandırma sonrasında sınıflandırılmış piksellerden frekansı en yüksek olan (en çok tekrarlanan) pikselin etiketi parsele sınıf etiketi olarak atanmıştır.
Altı farklı tarihte çekilen görüntülerin her birine ait K, Y, M, YKÖ ve NFBi bantlar birleştirilerek her bir görüntü için 5 bantlı görüntü yığını oluşturulmuştur. Sınıflandırma işlemi, altı farklı tarihe ait görüntülerin birlikte kullanılması suretiyle gerçekleştirilmiştir. Dolayısıyla, sınıflandırma işleminde toplam 30 banttan $(6 \times 5)$ oluşan görüntü yığını kullanılmıştır.

RO algoritması temel sınıf olarak karar ağacını kullanan topluluk algoritmalarından biridir (Breiman 2001 ve Horning 2011). RO algoritması ile sınıflandırma işleminde ilk olarak eğitim veri setinin $2 / 3^{\prime}$ ünden önyükleme örnekleri oluşturulur. Bu örnekler eğitim veri setlerini oluşturur ve ağaç gelişimi için kullanılır. Genelleştirilmiş hatalar (Out 
of Bag-OOB) verisi olarak da adlandırılan eğitim veri setinin $1 / 3^{\prime}$ lük geri kalan kısmı hataları test etmek için kullanılır. Ağaç gelişim işlemine başlamadan önce RO algoritmasını başlatmak için kullanıcı tarafından iki parametre tanımlanır. Bu parametreler, en iyi bölünmeyi belirlemek için her bir dügümme kullanılan değişkenlerin sayısı (mtry) ve geliştirilecek ağaçların sayısıdır (ntree). Kullanıcı tarafından başlangıç mtry değeri rastgele seçilir, sonraki mtry değerleri genelleştirilmiş hatalara (OOB) göre artırılır ya da azaltılır. Mtry değeri azalınca korelasyon ve güç azalır, artınca korelasyon ve güç artar. Bu şekilde en uygun mtry bulunur ve sınıflandırma duyarlılığı artar, hata azalır. Her bir düğümde mtry değişkenleri tüm değişkenler arasından rastgele olarak seçilir ve bu değişkenler arasından en iyi dal belirlenir. Yeterli öngörü gücü ile yeterli miktarda düşük korelasyon sağlayan değişken sayısının seçimi son derece önemlidir. Toplam değişken (bant) sayısının $M$ adet olduğu varsayılırsa, M sayısının kare köküne eşit alınan mtry değişken sayısı genel olarak optimum sonuca en yakın sonucu vermektedir (Horning 2011). Sonra, her bir önyüklemeli örnekten budama olmadan bu tanımlanan mtry ve ntree parametrelerine göre ağaçlar geliştirilir. Her bir ağacın oluşturulması için bu işlemler tekrarlanır. Orman oluşturulduktan sonra nesneler tüm ağaçlar tarafından sınıflandırılır ve tüm sınıflandırmaların çoğunluk (majority) değeri alınarak sonuç sınıf elde edilir (Liaw and Wiener 2002 ve Akar 2013). Bu çalışmada, ntree ve mtry parametre değerlerinin belirlenmesinde Breiman (2018), Breiman (2001), Pal (2005) ve Archer and Kimes (2008) tarafından yapılan çalışmalar baz alınmış olup ntree değeri 100 , mtry değeri ise $\sqrt{30}$ olarak alınmıştır.
Sınıflandırma işleminde orijinal K, Y, M, YKÖ bantlara ek olarak, hesaplanan NFBi bantları da kullanılmıştır. NFBi bantı hesaplaması Eşitlik 1'e göre yapılmıştır. Eşitlik 1'de YKÖ ve K sırasıyla, Yakın Kızıl Ötesi ve Kırmızı bantları temsil etmektedir.

$N F B \dot{\mathrm{I}}=\frac{Y K O \ddot{O}-K}{Y K O \ddot{O}+K}$

Yersel referans veri olarak hazırlanan 5803 adet ÇKS parselinden 3035 adedi eğitim verisi, 2768 parsel ise sınıflandırma doğruluğunun hesaplanması için test verisi olarak kullanılmıştır. Çalışma alanında ürün bazında parsellerden toplanan yersel referans veriler (eğitim ve test parselleri) Çizelge 2' de verilmiştir. Sınıflandırma için gerekli eğitim verisi örnekleri, eğitim verisi olarak ayrılan ÇKS parsellerinin içinden manuel yöntemle seçilmiştir. Alanda mısır, buğday, pamuk, nohut ve mercimek sınıflarına göre daha az ekili olan fıstık, armut, arpa, ayva, badem, ceviz, elma, erik, kayısı, kimyon, kiraz, nadas, nar, soya, şeftali, üzüm, yonca ve zeytin sınıflandırmada "diğer" isimli sınıfa dâhil edilmiştir. Bazı ürünlerin alanda ekili haldeki fotoğrafları Şekil $6^{\prime}$ da gösterilmiştir. Eğitim verisi olarak kullanılan ÇKS parsellerinin dağılıımı Şekil 7'de, elde edilen sınıflandırma sonucu Şekil 8' de gösterilmiştir.

Çizelge 2. Ürün bazında eğitim ve test parselleri dağııımı.

\begin{tabular}{lcc}
\hline Ürün & $\begin{array}{c}\text { Eğitim } \\
\text { Parselleri } \\
\text { Sayısı }\end{array}$ & $\begin{array}{c}\text { Test Parselleri } \\
\text { Sayısı }\end{array}$ \\
\hline Mısır & 764 & 702 \\
\hline Buğday & 1843 & 1768 \\
\hline Pamuk & 172 & 124 \\
\hline Nohut & 16 & 12 \\
\hline Mercimek & 60 & 48 \\
\hline Diğer & 180 & 114 \\
\hline TOPLAM & $\mathbf{3 0 3 5}$ & $\mathbf{2 7 6 8}$ \\
\hline GENEL TOPLAM & & $\mathbf{5 8 0 3}$ \\
\hline
\end{tabular}




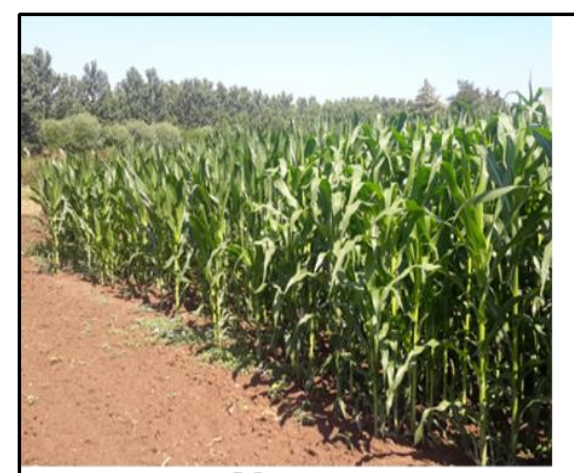

Misir

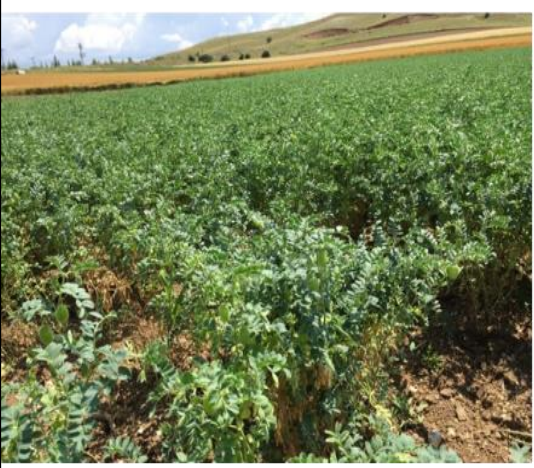

Nohut

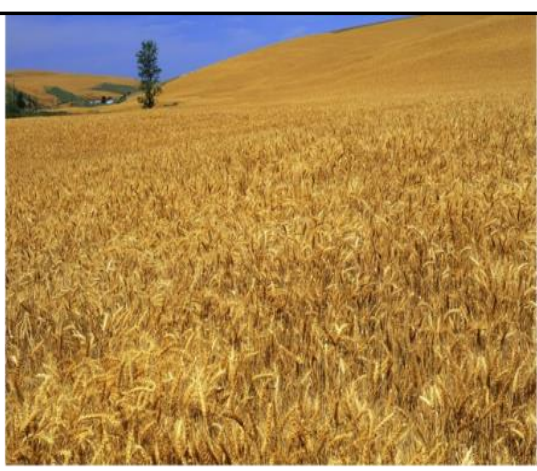

Bugday

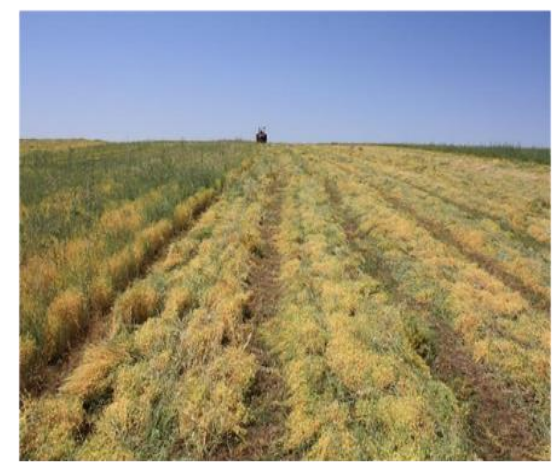

Mercimek

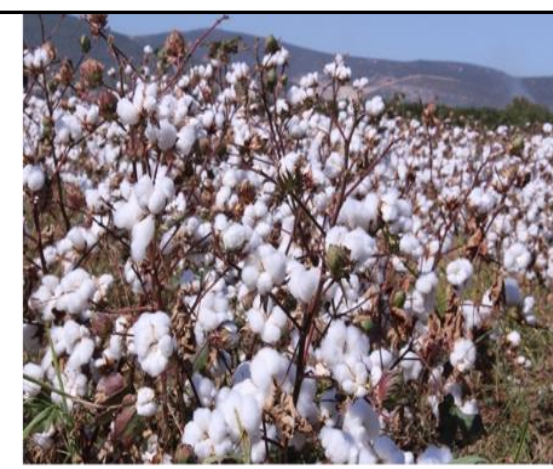

Pamuk

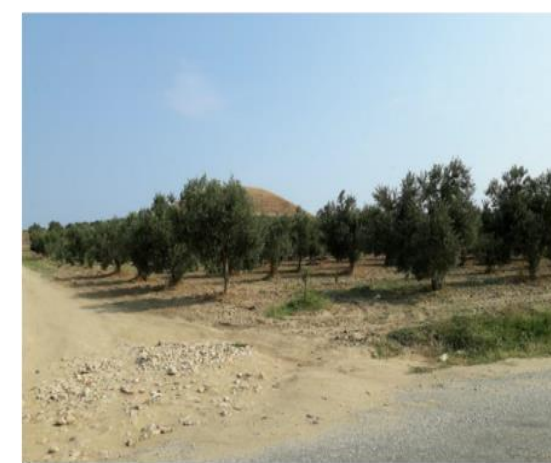

Diger (Zeytin Bahçesi)

Şekil 6. Çalışma alanında bulunan ürünlerin ekili haldeki görüntüleri.

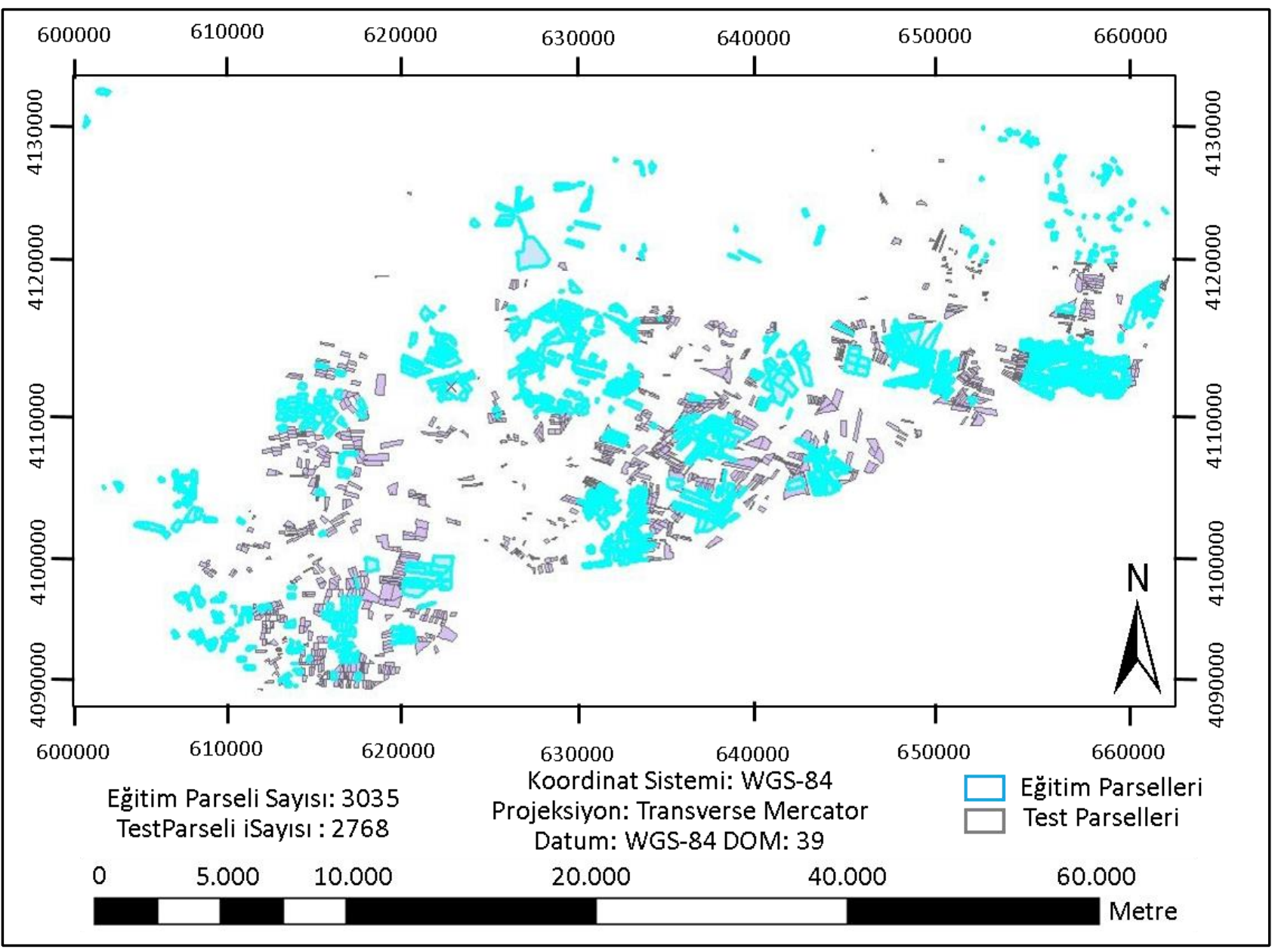

Şekil 7. ÇKS verisinden (siyah parseller) seçilen eğitim verisi parselleri (mavi parseller). 


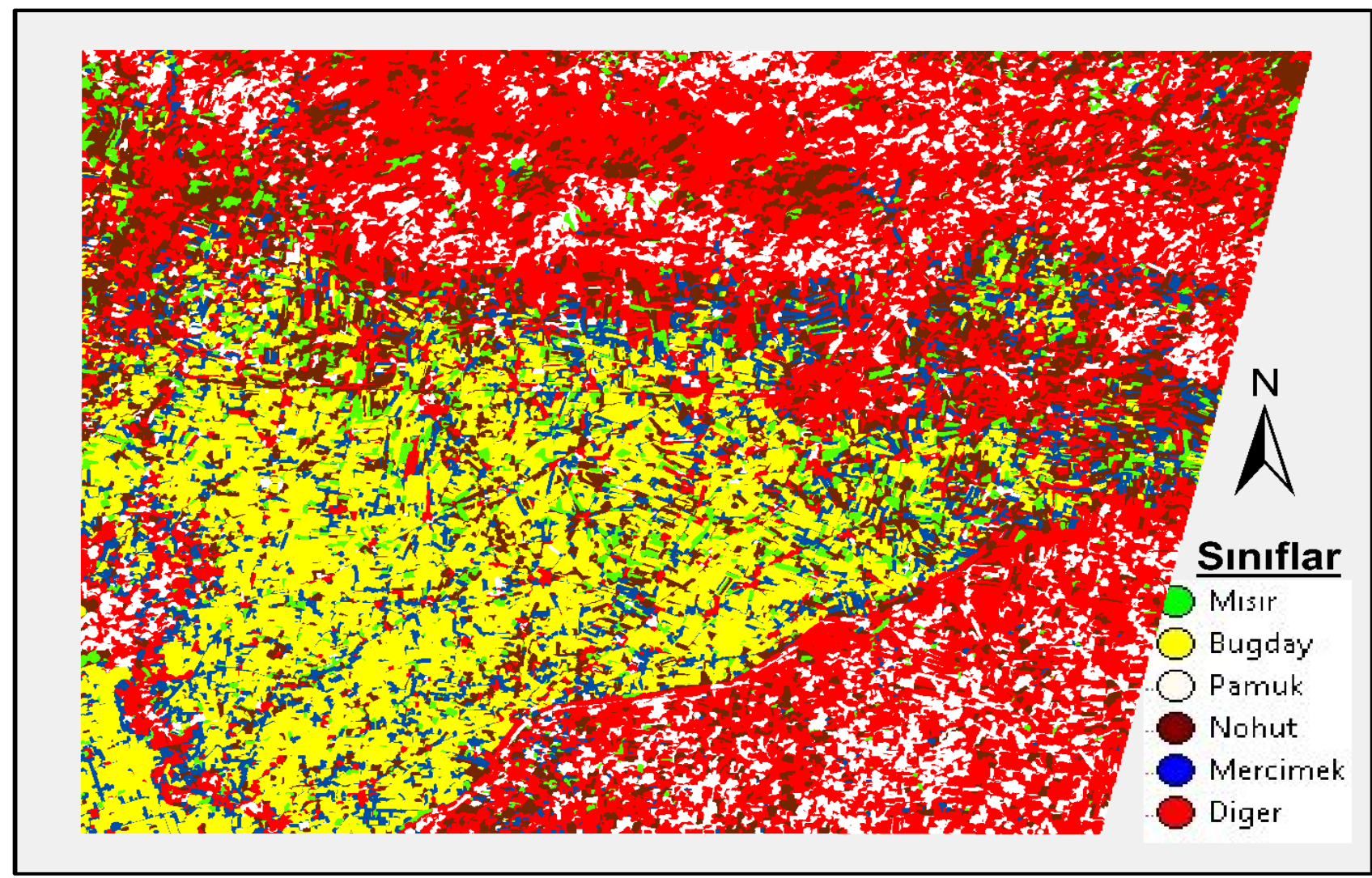

Şekil 8. RO makine öğrenme algoritması sınıflandırma sonucu.

Sınıflandırma genel doğruluğu ve Kappa katsayısı ile her bir sınıfa ait üretici ve kullanıcı doğrulukları hesaplanmış ve bir hata matrisi üzerinde gösterilmiştir. Hata matrisinin her bir sütunu ayrı bir sınıfa karşılık gelirken, satırlar referans verilerin atandıkları sınıfları temsil etmektedir. Buna göre $k$ tane sınıf için hata matrisi $k$ satır ve $k$ sütundan oluşur (Campbell and Wynne 1996). Bu çalışmada $\mathrm{k}$ (sınıf sayısı) 6'dır. Eşitlik 2, 3, 4, 5 ve 6'da yer alan n, toplam referans veri örüntü sayısıdır. nij, referans veride j kategorisindeyken $(\mathrm{j}=1,2, \ldots \ldots, \mathrm{k})$ sınıflandırıımış veri içinde $i$ sınıfına $(i=1,2, \ldots \ldots . . ., k)$ atanan örüntülerin sayısını gösterir. i kategorisine atanan sınıflandırma verisindeki örüntü sayısı Eşitlik 2'de, j kategorisi için referans verideki örüntü sayısı Eşitlik 3'de gösterilmiştir. Genel doğruluk değeri Eşitlik 4 'e göre hesaplanmıştır.

$$
\begin{aligned}
& n_{i+}=\sum_{i=1}^{k} n_{i j} \\
& n_{+j}=\sum_{i=1}^{k} n_{i j}
\end{aligned}
$$

Genel doğruluk $=\frac{\sum_{i=1}^{k} n_{i}}{\sum_{J=1}^{k} n_{+j}}=\frac{\sum_{i=1}^{k} n_{i i}}{n}$

Ayrıca, üretici ve kullanıcı doğrulukları da hesaplanmıştır. Üretici doğruluğu, doğru sınıflandırılmışörnek sayısının o kategoriye ait sütun sayısına bölünmesi ile hesaplanır (Eşitlik 5). Kullanıcı doğruluğu ise, doğru sınıflandırılmış örnek sayısının o kategori için olan satır sayısına bölünmesi ile hesaplanmaktadır (Eşitlik 6).

Üretici Doğruluğu $=\frac{n_{j j}}{n_{+j}}$

Kullanıcı Doğruluğu $=\frac{n_{i i}}{n_{i+}}$

Doğruluk analizlerinde kullanılan bir diğer ölçüt, Kappa katsayısıdır. Kappa katsayısı, hata matrisindeki genel doğrulukla olasılıklı doğruluk arasındaki farka dayanır. Sınıflar arası doğrulukları da içerdiğinden genel doğruluk ölçütünden daha iyi bir ölçüdür (Sunar vd. 2011). Kappa katsayısının hesaplanmasında Eşitlik 7 kullanılmıştır. 
Kappa katsayısı $(\kappa)=\frac{N * \sum_{i=1}^{k} x_{i j}-\sum_{i=1}^{k}\left(x_{i+} * x_{+j}\right)}{N^{2}-\sum_{i=1}^{k}\left(x_{i+} * x_{+j}\right)}$

Eşitlik 7 de, $N$ tüm kategorilerdeki örnek sınıf toplamını, ¿xij doğru sınıflandırılmış örnek sayısını, $\Sigma\left(x i+{ }^{*} x+j\right)$ ise her kategorideki hata matrisinin satır ve sütun toplamını ifade etmektedir. Buna göre değerlendiriciler arasındaki uyum ele alındığında, $k<0$ hiç uyum olmadığını, $0 \leq k \leq 0.20$ çok düşük bir uyumun olduğunu, $0.21 \leq k \leq 0.40$ düşük bir uyum olduğunu, $0.61 \leq \kappa \leq 0.80$ yüksek bir uyum olduğunu ve $0.81 \leq k \leq 1.00$ mükemmel bir uyum olduğunu göstermektedir. Bununla birlikte, 0.70 'den daha büyük bir Kappa katsayısı için değerlendiriciler arasındaki uyumun yeterli olduğu da söylenebilir (Cohen 1960).

\section{Bulgular ve Tartışma}

Hesaplanan genel doğruluk ve Kappa katsayısı değerleri ile üretici ve kullanıc doğruluk değerleri
Çizelge 3' de verilmiştir. Hesaplanan genel doğruluk değeri (\% 96.35), bir bütün olarak çalışma alanında bulunan tarımsal ürünlerin RO sınıflandırma algoritması ile çok yüksek doğrulukla tespit edildiğini göstermektedir. Bu durum neredeyse fiziksel olarak çalışma alanındaki gerçek parsellerin doku özelliği ile birebir aynı olarak tarımsal ürün deseninin tespit edildiğini gözler önüne sermektedir.

Sınıflandırma sonrası oluşturulan hata matrisinden hesaplanan \% 93.13 oranlı kappa katsayısı istatistiki sayısal verisi yorumlandığında, bu çalışmada gerçek fiziksel yeryüzü oranı 1.0000 kabul edildiğinde, çalışma alanındaki tarımsal üretim yapılan parsellerin oluşturduğu sınıflandırma sonucunda elde edilen tematik harita üzerinde oluşan desene 0.9313 oranı ile doğru bir şekilde yaklaşarak, 0.0687 (1.0000 - 0.9313) oranında doğru olan tarımsal ürün deseninden uzaklaşma vardır şeklinde bir değerlendirme yapılabilir.

Çizelge 3. Genel doğruluk, Kappa katsayısı, üretici ve kullanıcı doğruluk değerlerini gösteren hata matrisi.

\begin{tabular}{|c|c|c|c|c|c|c|c|c|c|}
\hline & \multirow{2}{*}{$\begin{array}{c}\text { Parsel sayıları } \\
\text { Sınıflar }\end{array}$} & \multicolumn{8}{|c|}{ Referans Veri } \\
\hline \multirow{9}{*}{ 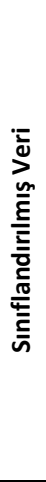 } & & Mısır & Buğday & Pamuk & Nohut & Mercimek & Diğer & Toplam & $\begin{array}{c}\text { Kullanıcı } \\
\text { Doğruluğu (\%) }\end{array}$ \\
\hline & Misır & 696 & 6 & 4 & 1 & 0 & 1 & 708 & 98.30 \\
\hline & Buğday & 3 & 1711 & 12 & 1 & 2 & 2 & 1731 & 98.84 \\
\hline & Pamuk & 1 & 7 & 101 & 1 & 1 & 0 & 111 & 90.99 \\
\hline & Nohut & 0 & 16 & 4 & 8 & 0 & 0 & 28 & 28.57 \\
\hline & Mercimek & 0 & 2 & 0 & 0 & 40 & 0 & 42 & 95.23 \\
\hline & Diğer & 2 & 26 & 3 & 1 & 5 & 111 & 148 & 75.00 \\
\hline & Toplam & 702 & 1768 & 124 & 12 & 48 & 114 & 2768 & \\
\hline & $\begin{array}{c}\text { Üretici } \\
\text { Doğruluğu (\%) }\end{array}$ & 99.14 & 96.77 & 81.45 & 66.67 & 83.34 & 97.36 & $\begin{array}{l}\text { Genel Do } \\
\text { Kappa Ka }\end{array}$ & $\begin{array}{l}\text { uk (\%) }=96.35 \\
\text { ISI (\%) }=93.13\end{array}$ \\
\hline
\end{tabular}

Çizelge 3 'de verilen doğruluk değerlerine göre mısır için üretici doğruluğu \% 99.14, kullanıcı doğruluğu \% 98.30 olarak hesaplanmıştır. Mısır için hesaplanan doğruluk değerlerinin oldukça yüksek olduğu ve neredeyse gerçekte mısır ekili olan tüm tarım parsellerinin doğru olarak tespit edildiği görülmektedir. Mısır sınıfına ait 702 referans parselin sınıflandırma neticesinde 696 tanesi doğru olarak mısır sınıfına, 3 tanesi yanlış olarak buğday sınıfına, 1 tanesi yanlış olarak pamuk sınıfına ve 2 tanesi yanlış olarak diğer sınıfa atanmıştır. Mısır için, 3 parselin buğday, 1 parselin pamuk ve 2 parselin ise diğer olmak üzere toplamda 6 parselin yanlış olarak sınıflandırıldığı, bir başka ifade ile, olması gereken sınıftan başka sınıflara atanarak kaçış hatası bulgusuna (error of omission) sebep olduğu saptanmıştır. Kaçış hatası (error of omission) yüzdelik değeri 100 - kullanıc doğruluğu işlemi ile hesaplanmıştır. Dolayısıyla, mısır için kaçış hatası $100-98.30=\% 1.70$ olarak bulunmuştur.

Buğday için üretici doğruluğu \% 96.77 ve kullanıcı doğruluğu \% 98.84 olarak hesaplanmıştır (Çizelge 3). Buğday sınıfına ait 1768 referans parselin sınıflandırma neticesinde 1711 tanesi doğru olarak buğday sınıfına, kalan 57 tanesi ise mısır, pamuk, 
nohut, mercimek ve diğer sınıflarına atanarak yanlış sınıflandırımıştır. Dolayısıyla, buğday için kaçış hatası $100-98.84=\% 1.16$ olarak hesaplanmıştır.

Pamuk için toplam referans parsel sayısı 124, üretici ve kullanıcı doğrulukları sırasıyla \% 81.45 ve \% 90.99 'dur. 124 adet pamuk parselinden, mısır ve buğday ile karşılaştırıldığında, en yüksek oranda kaçıs 12 parsel ile buğday sınıfına olmuştur. Pamuk sınıfından mısır ve nohut sınıfının her ikisine kaçış parsel sayısı 4, diğer sınıfına kaçış parsel sayısı 3 ve toplam kaçış parsel sayısı 23'tür. Pamuk için kaçış hatası $100-90.99=\% 9.01$ olarak hesaplanmıştır.

Mercimek için kullanılan toplam 48 parselin 40 tanesi mercimek olarak doğru sınıflandırılmıştır. Olması gerekenden farklı sınıflara atanmış 8 parselin 2'si buğday, 1 'i pamuk ve 5 'i ise diğer sınıf etiketini alarak kaçış hatasına neden olmuşlardır. Mercimek sınıfının üretici ve kullanıcı doğrulukları sırasıyla \% 83.34 ve \% 95.23 olarak hesaplanmıştır. Mercimek için kaçış hatası $100-95.23=\% 4.77$ olarak hesaplanmıştır.

Çalışma alanında bulunan parsel sayısı açısından dikkate alındığında, daha az ekili olan diğer sınıf kategorisine ait 114 referans parselden 111 tanesi diğer sınıf etiketini alarak, olması gereken sınıfa atanmıştır. Çok yüksek oranda doğru sınıflandırılan diğer sınıfının üretici doğruluğu \% 97.36, kullanıcı doğruluğu ise \% 75.00 olarak hesaplanmıştır. Kaçış hatasına neden olan 3 parselin 1 tanesi mısır, 2 tanesi ise buğday sınıfına gitmiştir. Diğer sınıf için kaçış hatası $100-75.00=\% 25.00$ olarak hesaplanmıştır.

Nohut için üretici doğruluğu \% 66.67, kullanıcı doğruluğu \% 28.57 olarak hesaplanmıştır. Hesaplanan bu değerlerin, nohut ürününe ait referans veride eğitim ve test verisi olarak seçilebilecek parsellerin sayıca diğer ürünlere göre çok daha az olmasından kaynaklanabileceği tahmin edilmektedir. Nohut'a ait 12 referans parselden 8 tanesi doğru sınıflandırılmış, 4 tanesi ise eşit sayıda mısır, buğday, pamuk ve diğer sınıflara giderek kaçış hatasına neden olmuştur. Nohut'a ait referans parsel sayısının sayıca düşüklüğü nedeniyle bu durum normal karşılanmıştır.

Çalışma alanında nohudun öteki ürünlere göre daha az ekili olması gerçeği bu durumu haklı çıkarmıştır. Çalışma alanında ekili alanlardaki ürünlerin hem parsel sayısı hem de alansal yüzölçümü olarak miktarlarının en yüksekten aşağıya doğru sıralanışı şu şekildedir: Buğday, Mısır, Pamuk, Mercimek, Diğer (fıstık, armut, arpa, ayva, badem, ceviz, elma, erik, kayısı, kimyon, kiraz, nadas, nar, soya, şeftali, üzüm, yonca, zeytin) ve Nohut. Nohut için kaçış hatası $100-28.57=\% 71.43$ olarak hesaplanmıştır.

Nohut için hesaplanan kullanıcı doğruluğuna (\%28.57) göre daha yüksek olan üretici doğruluğu (\% 66.67), referans veride nohut olan parsellerin makul bir düzeyde doğru sınıflandırıldığını göstermektedir. Ancak, düşük oranda olan kullanıcı doğruluğu, nohut olarak sınıflandırılan parsellerin gerçekte nohut ekili alanlar ile uyuşum seviyesinin düşük olduğunu göstermektedir. Bu durumun nohut ve buğday ürünlerinin ekim, gelişim ve hasat zamanlarının birbirine yakın olması nedeniyle, bu iki sınıfın birbirine yakın yansıma değerleri vermesinden ve bu nedenle algoritmanın bu iki sınıfı birbirinden ayıramamasından kaynaklandığı düşünülmektedir. Şekil 9'da, çoklu zamanlı görüntülerin NFBi bantlarından her bir sınıf için hesaplanmış spektral ayrılma eğrileri gösterilmiştir. 


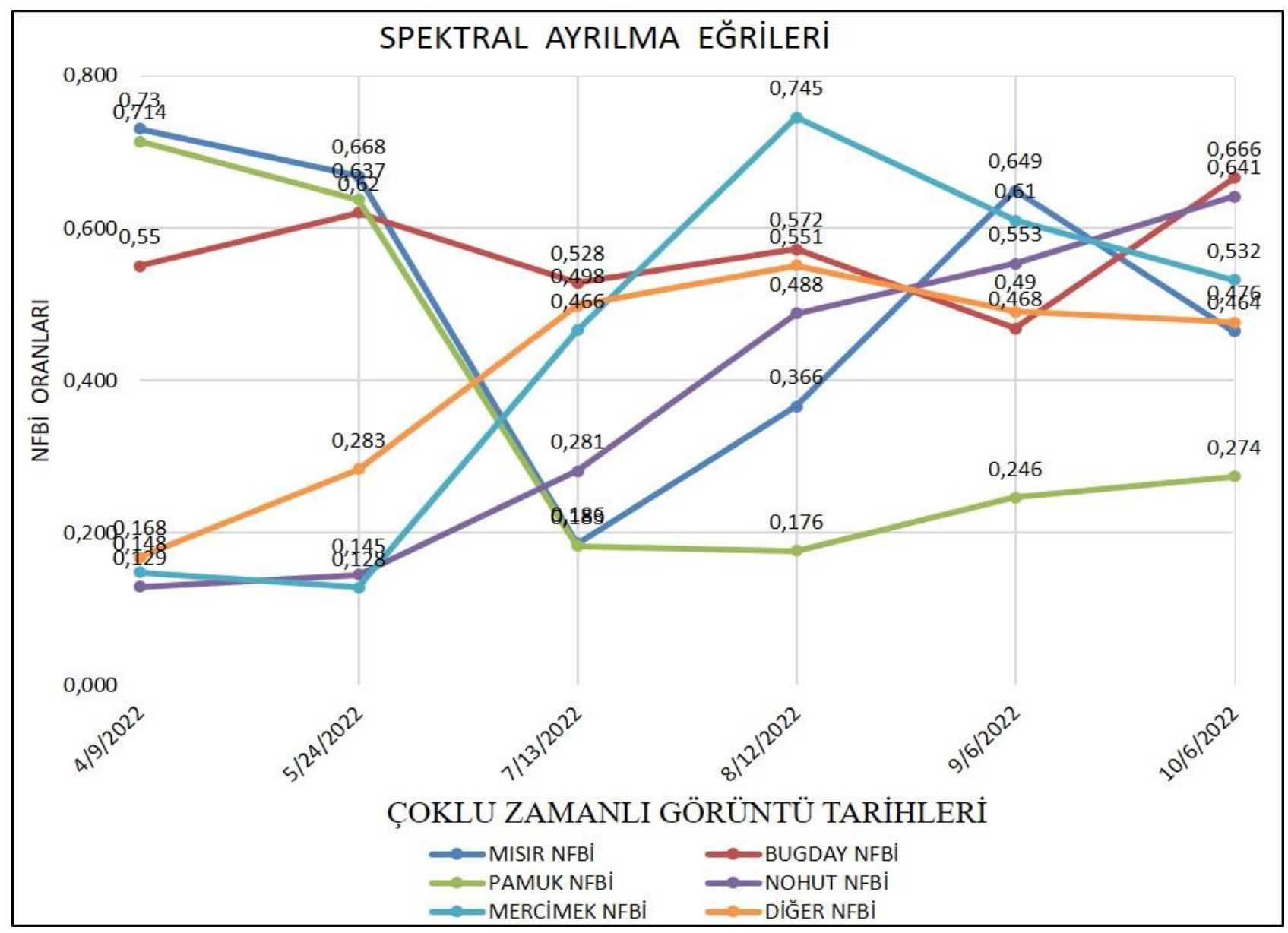

Şekil 9. Ürünlerin NFBi bant oranlarının çoklu zamanlı tarihlere göre değişimi.

Şekil 10 (a) gerçek renkli (true color-KYM) görüntü, (b) ise (a)'nın sınıflandırma sonucu elde edilen tematik haritası olup nohut ve buğday sınıflarının birbirine karıştığına ait örnektir. Şekil 10 (c) de benzer şekilde bir gösterim olup, pamuk, nohut ve diğer sınıfına ait parsellerin birbirine karıştığına ait örnek biçimdir. Şekil 10 (f) ise, Şekil 10 (e) uydu görüntüsüne göre buğday ekili bir parselin ortasında nohut, üst kenarda buğday ve alt kenarda ise mısır ürünü olduğunu temsil eden gösterimdir ve tek bir parsel içerisinde üç farklı ürünün birbiriyle karıştığına ilişkin bir örnektir. Şekil 10 (a,b,c,d,e ve f) bir yönüyle Çizelge 3'de verilen sayısal verilerin ve her bir sınıfın kaçış hatasını (error of omission) görsel olarak destekleyen bir kanıttır. 


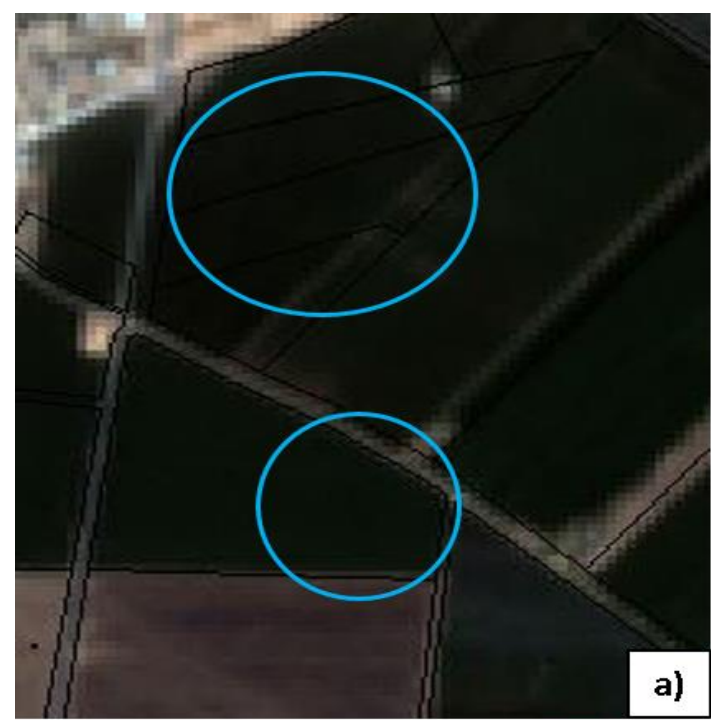

Nohut

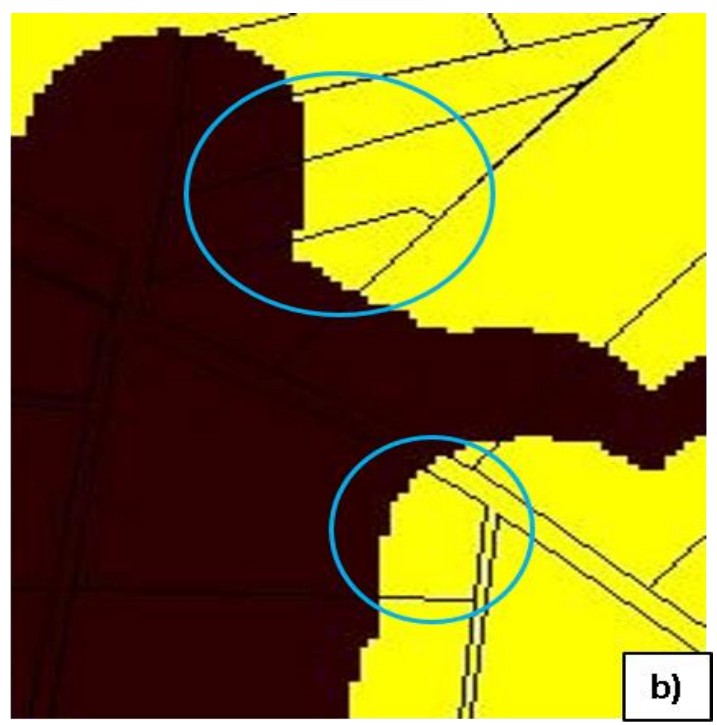

Buğday
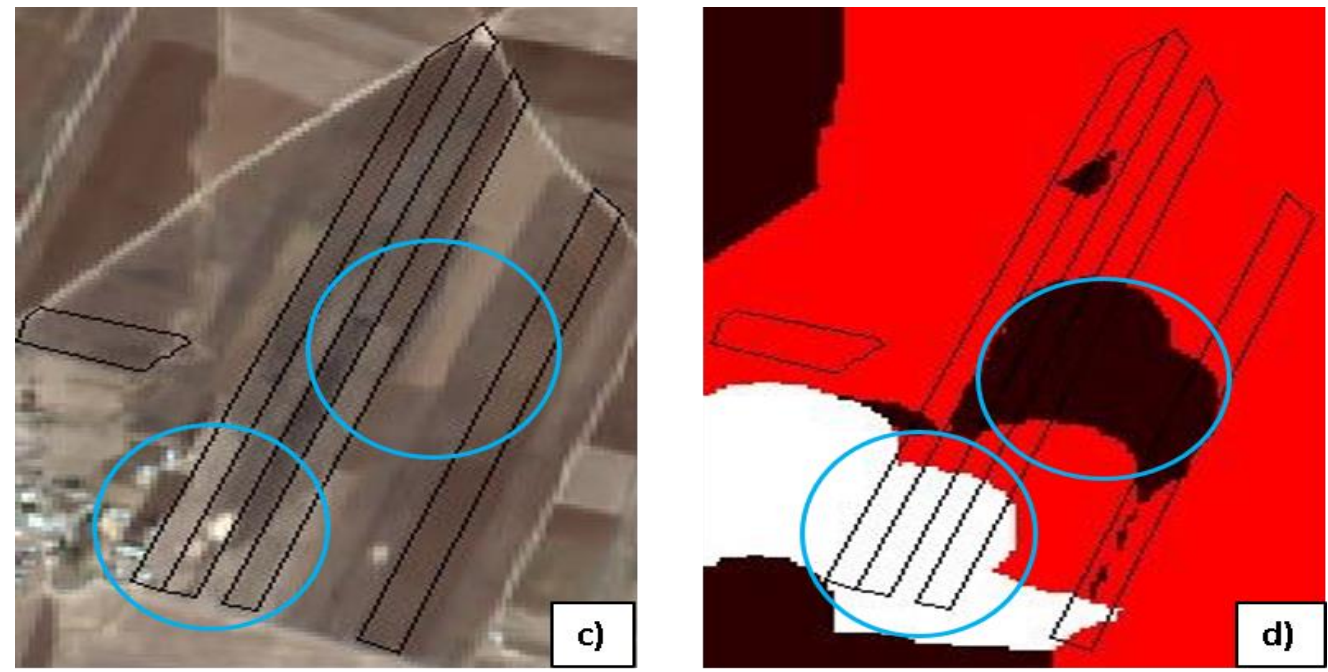

Nohut $\square$ Pamuk

\section{Diğer}
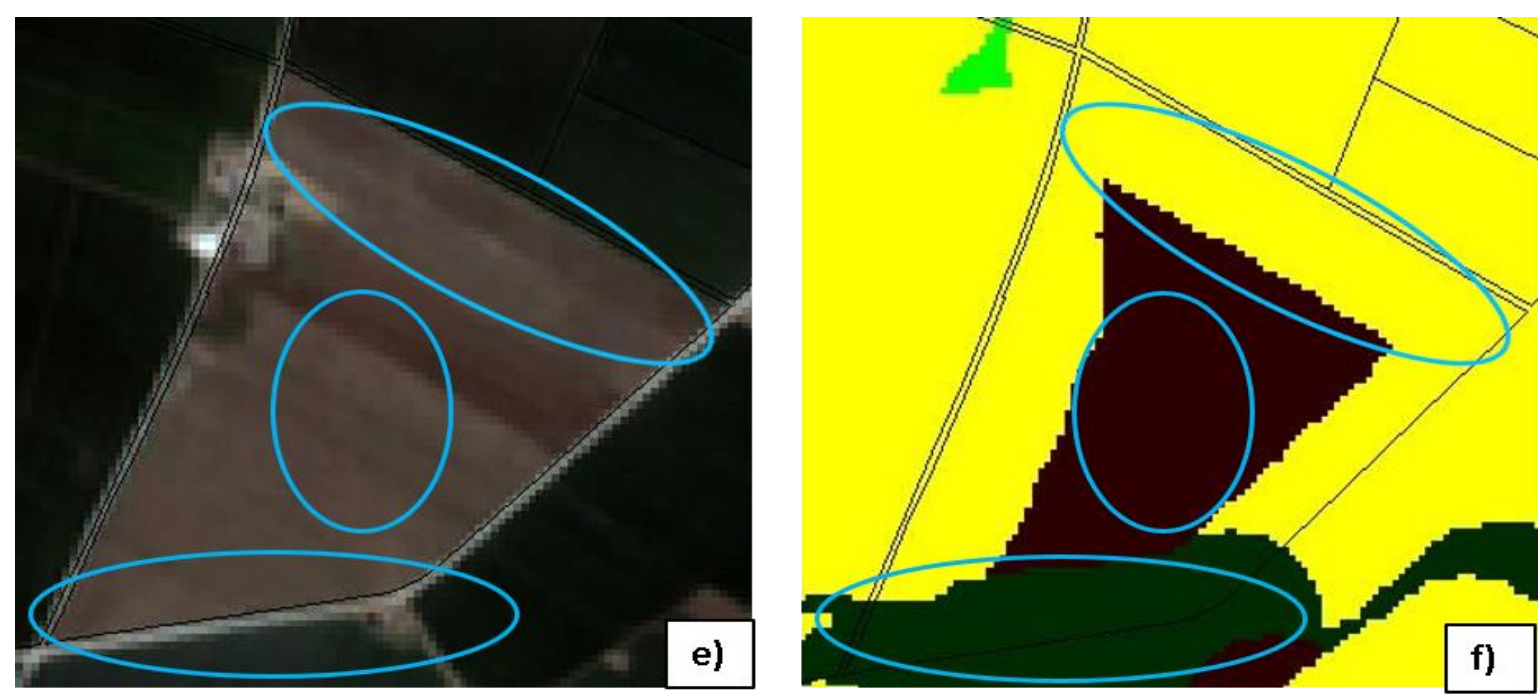

Buğday

Nohut

Misır

a), c), e):Uydu görüntüsü üzerindeki parsellerin görünümü.

b), d), f): Birbirine karışan sınıfları gösteren görüntü ve sınıflandırma sonucu kesitleri.

Şekil 10. Birbirine karışan sınıfları gösteren görüntü ve sınıflandırma sonucu kesitler. 
Tarımsal ürünlerin uydu görüntülerden otomatik sınıflandırmasında ürünlerin ekim, gelişim ve hasat tarihlerinde çok zamanlı görüntü alımının yapııması, ürünler arasındaki farklı zamansal değişimleri ortaya koyduğu için, önemlidir. Tek bir tarihte alımı yapılmış bir görüntü ile yapılacak sınıflandırma işlemi, tarımsal ürünlerin farklı tarihlerdeki zamansal değişimini yansıtmadığı için yetersiz kalmaktadır (Gömez vd. 2016, Long vd. 2013). Bu nedenle, tarımsal ürünleri ayırabilmek için ürünlerin ayırıcı dönemlerini içeren tarihlerde görüntülerin alınması önem arz etmektedir. Fakat; özellikle tespit edilmek istenen belirli bir ürün varsa sadece o ürünün diğerlerinden ayrılabildiği tarihe ait görüntü alımı yapııması ve o ürünü ayıran ilgili spektral ve diğer özelliklerin kullanılması gerekmektedir.

Görüntülere ücretsiz olarak ulaşılabilmesi, $10 \mathrm{~m}$ çözünürlüklü bantların belirli büyüklükteki tarım parsellerinin bulunduğu bölgelerdeki tarımsal uygulamalar için yeterli olması ve 5 gün gibi yüksek zamansal çözünürlüğe sahip olması, Sentinel 2 verilerini tarımsal ürün tespiti için çok değerli hale getirmiştir. Referans veriler makine öğrenme algoritmalarında oluşturulan modelin eğitilmesinde kullanılmaktadır. Referans verileri elde etmek için araziye gidilip çalışma yapılmasına ya da araziden toplanan referans veri yerine geçebilecek tarım parselleri ürün bilgisine ihtiyaç duyulmaktadır. Ülkemizde, çiftçilere ait tarımsal faaliyetler T.C. Tarım ve Orman Bakanlığı'nca oluşturulan Çiftçi Kayıt Sistemi (ÇKS) veri tabanı ile kayıt altına alınmaktadır. Bu çalışmada elde edilen deneyimler, ÇKS verilerinin uydu görüntülerinden otomatik sınıflandırma ile ürün deseni tespitinde referans veriler olarak kullanılabileceğini göstermiştir. Ancak, bu verilerin öncelikle mutlak suretle birtakım editleme işlemlerinden ve analizlerden geçirilmesi gerekmektedir.

\section{Sonuçlar}

Bu çalışmada, Mardin Iili, Artuklu, Kızıltepe ve Derik ilçelerine ait bir tarımsal alanda, 2018 yılına ait çoklu tarihli Sentinel 2 uydu görüntülerinden RO algoritması kullanılarak parsel-tabanlı yaklaşımla tarımsal yaz ürünlerinin tespiti yapılmıştır.
Sınıflandırmada $10 \mathrm{~m}$ çözünürlüklü $K, Y, M$ ve YKÖ bantların yanı sıra, her bir görüntü tarihi için hesaplanan NFBi bantları ek bantlar olarak kullanılmıştır. Sınıflandırmada, her bir görüntü tarihine ait beş bant (K, Y, M, YKÖ ve NFBi) olmak üzere, toplam 30 bantlı yığın aynı anda kullanılmıştır. Eğitim ve test verileri için mevcut ÇKS verilerinden yararlanılmıştır.

08.04.2018, 23.05.2018, 12.07.2018, 11.08.2018, 05.09.2018 ve 05.10.2018 olmak üzere altı farklı tarihe ait seçilen görüntüler ile çalışma alanından elde edilen sınıflandırma doğruluk oranları oldukça tatmin edicidir. Sınıflandırma sonucu istatistiksel doğruluk değerleri genel doğruluk ve kappa katsayısı sırasıyla \% 96.35 ve \% 93.13 olarak hesaplanmıştır.

Mısır, \% 99,14 üretici doğruluğu ve \% 98,30 kullanıcı doğruluğu ile en başarılı tespit edilen ürün olmuştur. Nohut, \% 66.67 üretici doğruluğu ve \% 28.57 kullanıcı doğruluğu ile en düşük doğrulukla sınıflandırılan ürün olmuştur. Bunun nedeni olarak, kullanılan RO sınıflandırma algoritmasının kararsız kalmasından dolayı, özellikle buğday ve mısır sınıfı ile nohudun karışmasından kaynaklı uyumun düşük olduğu sonucuna varılmıştır.

Ürünlerin ekimi ve hasadı arasında seçilen altı görüntü tarihine ait bantların sınıflandırması için belirlenen RO parametreleri ağaç sayısı (ntree) değeri (100) ve rastgele değişken sayısı (mtry) parametre değeri $(\sqrt{30})$ ile bu çalışmada ulaşılan doğruluk oranları oldukça tatminkârdır. $\mathrm{Bu}$ sonuçlara göre, bu parametre değerlerinin bu çalışma alanı için uygun değerler olduğu sonucuna varılmıştır.

Intel Core Duo T6400 2.0 Ghz işlemci, ATI Mobility Radeon HD 3650 Max. 2302 MB GPU kartı, 4 Gb RAM ve 320 GB HDD sabit disk özelliklerine sahip bir dizüstü bilgisayarda bu çalışma alanını kapsayan 4816 satır $\times 6898$ sütun genişlikli, 10m çözünürlüklü, 30 bantlı görüntü yığını ile yapılan sınıflandırma işlemi yaklaşık 1 saat 32 dakika sürmüştür.

ÇKS verilerinin sınıflandırma işlemi doğruluk değerlendirmesinde kullanılması bu çalışmada önemli bir adım olmuştur. Ancak, görüntüler ile birlikte görsel olarak analiz edildiğinde, ÇKS verisinin 
referans veri olarak kullanılabilmesi için, ön işlemelerden geçirilmesi gerektiği ortaya çıkmıştır.

ÇKS veri tabanı tarım parselleri maliklerinin sözlü beyanlarına göre oluşturulduğu için, veride hatalar olabilmektedir. Bu çalışmada elde edilen sonuçlar, çiftçiler tarafından ekildiği beyan edilen ürünlerin belli düzeyde kontrollerinin, çoklu zamanlı Sentinel 2 uydu görüntülerin RO algoritması ile sınıflandırması ile yapılabileceğini göstermiştir.

Tarımsal yaz ürünlerinin tespiti uygulaması olarak yapılan bu çalışmada kullanılan Sentinel 2 uydu görüntüleri oldukça başarılı sonuçlar üretmiştir. Ücretsiz erişim sağlanan ve bu nedenle çok avantajlı olan Sentinel 2 görüntüleri, yüksek doğruluk üretmesinden dolayı, bölgede yaygın olarak benzer çalışmalarda kullanıla bilinir.

Bundan sonra yapılacak çalışmalarda, bölgeye ait çoklu zamanlı uydu görüntülerinden farklı ürünlerin tespitinde diğer makine öğrenmesi algoritmaların performanslarının ortaya çıkarılması hedeflenmektedir.

\section{Teşekkür}

Bu çalışmada kullanılan ÇKS verilerini sağlayan T.C. Tarım ve Orman Bakanlı̆̆ı'na çok teşekkür ederiz.

\section{Kaynaklar}

Akar, Ö., 2013. Rastgele Orman Sınıflandırıcısına Doku Özellikleri Entegre Edilerek Benzer Spektral Özellikteki Tarımsal Ürünlerin Sınıflandırılması. Doktora Tezi, Karadeniz Teknik Üniversitesi, Fen Bilimleri Enstitüsü, Trabzon, 180.

Archer, K.J. and Kimes, R.V., 2008. Emprical characterization of random forest variable importance measure. Computational Statistics \& Data Analysis, 52 (4), 2249-2260.

Arvor, D., Jonathan, M., Meirelles, M. P., Dubreuil V. and Durieux, L., 2011. Classification of MODIS EVI time series for crop mapping in the state of Mato Grosso, Brazil. International Journal of Remote Sensing, 32, 7847-7871.
Ban, Y., 2003. Synergy of multitemporal ERS-1 SAR and Landsat TM data for classification of agricultural crops. Canadian Journal of Remote Sensing, 29, 518526.

Belgiu, M. and Csillik, O., 2018. Sentinel-2 cropland mapping using pixel-based and object-based timeweighted dynamic time warping analysis. Remote Sensing of Environment, 204, 509-523.

Breiman, L., 2018. Manual on setting up, using and understanding random forests. RColorBrewer MASS, 3 (1), 1-33

Breiman, L., 2001. Random forests. Machine Learning Kluwer Academic Publishers, 45, 5-32.

Brisco, B. and Brown, R. J., 1995. Multidate SAR/TM synergism for crop classification in western Canada. Photogrammetric Engineering and Remote Sensing, 61 (8), 1009-1014.

Campbell, J.B. and Wynne, R.H. 1996. Introduction to Remote Sensing. The Guilford Press, 408-429.

Cohen, J., 1960. A coefficient of agreement for nominal scales, Educational and Psychological Measurement, 20 (1), 37-46.

Dheeravath, V., Thenkabail, P.S., Chandrakantha, G., Noojipady, P., Reddy, G.P.O., Biradar, C.M., Gumma, M.K. and Velpuri, M., 2010. Irrigated areas of India derived using MODIS $500 \mathrm{~m}$ time series for the years 2001-2003. ISPRS Journal of Photogrammetry and Remote Sensing, 65 (1), 42-59.

Gasparovic, M. and Jogun, T., 2017. The effect of using Sentinel-2 bands on land-cover classification. International Journal of Remote Sensing, 39 (3), 822 841.

Gömez, C., White J.C. and Wulder, M. A., 2016. Optical remotely sensed time series data for land cover classification: a review. ISPRS Journal of Photogrammetry and Remote Sensing, 116, 55-72.

Gumma, M. K., Nelson, A., Thenkabail P. S. and Singh, A. N., 2011. Mapping rice areas of South Asia using MODIS multitemporal data. Journal of Applied Remote Sensing, 26, 1-27. 
Horning, N., 2011. Random forests: An algorithm for image classification and generation of continuous fields data sets. International Conference on Geoinformatics for Spatial Infrastructure Development in Earth and Allied Sciences (GIS-IDEAS).

Immitzer, M., Vuolo, F. and Atzberger, C., 2016. First Experience with Sentinel-2 Data for Crop and Tree Species Classifications in Central Europe. Remote Sensing, 8, 166-193.

Inglada, J., Vincent, A., Arias M. and \& Marais-Sicre, C., 2016. Improved early crop type identification by joint use of high temporal resolution sar and optical image time series. Remote Sensing, 8 (5), 362-383.

İrfanoğlu, F., ve Balçık, F. B., 2018. Arazi örtüsü ve arazi kullanımı sınıflarının sentinel-2 görüntüsü ve nesne tabanlı sınıflandırma yöntemiyle belirlenmesi. VII. Uzaktan Algılama-CBS Sempozyumu.

Liaw, A. and Wiener, M., 2002. Classification and regression by random forest, $R$ News, 2 (3), 18-22.

Long, J.A., Lawrance, R. L., Greenwood, M. C., Marshall, L. and Miller, P.R., 2013. Object-oriented crop classification using multitemporal ETM+ SLC-off imagery and random forest. Remote Sensing, 50, 418436.

Noi, P.T. and Kappas, M., 2018. Comparison of random forest, k-nearest neighbor, and support vector machine classifiers for land cover classification using sentinel-2 imagery. Remote Sensing, 18 (1), 18-38.

Pal, M., 2005. Random forest classifier for remote sensing classification. International Journal of Remote Sensing, 26 (1), 217-222.

Peña-Barragán, J. M., Ngugi, M. K., Plant R. E. and Six, J., 2011. Object-based crop identification using multiple vegetation indices, textural features and crop phenology. Remote Sensing of Environment, 115, 1301-1316.

Pirotti, F., Sunar, F. and Piragnolo, M., 2016. Benchmark of machine learning methods for classification of a sentinel-2 image. The International Archives of the Photogrammetry and, Remote Sensing and Spatial Information Sciences, 41, 335-340.
Powell, S. L., Pflugmacher, D., Kirschbaum, A.A., Kim, Y. and Cohen, W.B., 2007. Moderate resolution remote sensing alternatives: a review of Landsat-like sensors and their applications. Journal of Applied Remote Sensing, 1 (1), 1-16.

Rodriguez-Galiano, V. F., Ghimire, B., Rogan, J., ChicaOlmo, M. and Rigol-Sanchez, J. P., 2012. An assessment of the effectiveness of a random forest classifier for landcover classification. ISPRS Journal of Photogrammetry and Remote Sensing, 67, 93-104.

Sakamoto, T., Yokozawa, M., Toritani H. and Shibayama, M., 2005. A crop phenology detection method using time-series MODIS data. Remote Sensing of Environment, 96, 366-374.

Simonneaux, V., Duchemin, B., Helson, D., Er-Raki, S., Olioso, A. and Chehbouni, G. A., 2008. The use of highresolution image time series for crop classification and evapotranspiration estimate over an irrigated area in central Morocco. International Journal of Remote Sensing, 29 (1), 95-116.

Sonobe, R., Yamaya, Y., Tani, H., Wang, X., Kobayashi N. and Mochizuki, K., 2017. Assessing the suitability of data from sentinel-1A and $2 A$ for crop classification. GIScience \& Remote Sensing, 54 (6), 918-938.

Sunar, F., Özkan, C. ve Osmanoğlu, B., 2011. Uzaktan Algılama. Prof. Dr. Filiz Sunar (Editör), Anadolu Üniversitesi Yayınları, 150-178.

Thenkabail, P. S., Hanjra, M. A., Dheeravath, V. and Gumma, M., 2010. A holistic view of global croplands and their water use for ensuring global food security in the 21st century through advanced remote sensing and non-remote sensing approaches. Remote Sensing, 2, 211- 261.

Thenkabail, P. S., Hanjra, M. A., Dheeravath, V. and Gumma, M., 2011. Advances in Environmental Remote Sensing: Sensors, Algorithms and Applications. Qihao Weng (Editor), CRC Press, 383419.

Thenkabail, P. and Wu, Z., 2012. An automated cropland classification algorithm (ACCA) for Tajikistan by combining Landsat, MODIS, and secondary data. Remote Sensing, 4, 2890-2918. 
Topaloğlu, R. H., Sertel, E. and Musaoğlu, N., 2016. Assessment of classification accuracies of sentinel-2 and Landsat-8 data for land cover/use mapping. The International Archives of the Photogrammetry, Remote Sensing and Spatial Information Sciences, 41, 1055-1059.

Turker, M. and Arikan, M., 2005. Sequential masking classification of multi-temporal Landsat7 ETM+ images for field-based crop mapping in Karacabey Turkey. International Journal of Remote Sensing, 26 (17), 3813-3830.

Vuolo, F., Neuwirth, M., Immitzer, M., Atzberger, C. and $\mathrm{NgW}, \mathrm{T} ., 2$ 2018. How much does multi-temporal Sentinel-2 data improve crop type classification?.
International Journal Earth Observation Geoinformation, 72, 122-130.

Wesseling, J. G. and Fedes, R. A., 2006. Assessing crop water productivity from field to regional scale. Agricultural Water Management, 86 (1), 30-39.

\section{internet kaynakları}

1-https://sentinel.esa.int/web/sentinel/user-guides. (03.05.2020).

2-https://desktop.arcgis.com/en/documentation/ (03.05.2020).

3- https://www.mathworks.com/ (03.05.2020). 